Article

\title{
Diverse Horizontally-Acquired Gene Clusters Confer Sucrose Utilization to Different Lineages of the Marine Pathogen Photobacterium damselae subsp. damselae
}

\author{
Saqr Abushattal ${ }^{\circledR}$, Ana Vences $\left({ }^{\circ}\right.$, Alba V. Barca ${ }^{\circledR}$ and Carlos R. Osorio *® \\ Departamento de Microbioloxía e Parasitoloxía, Instituto de Acuicultura, Universidade de Santiago de \\ Compostela, 15782 Santiago de Compostela, Spain; saqr.sulieman@usc.es (S.A.); ana.vences@usc.es (A.V.); \\ albavazquez.barca@usc.es (A.V.B.) \\ * Correspondence: cr.osorio@usc.es
}

Received: 17 September 2020; Accepted: 19 October 2020; Published: 22 October 2020

\begin{abstract}
The ability to metabolize sucrose is a variable trait within the family Vibrionaceae. The marine bacterium Photobacterium damselae subsp. damselae ( $P d d)$, pathogenic for marine animals and humans, is generally described as negative for sucrose utilization $\left(\mathrm{Scr}^{-}\right)$. Previous studies have reported sucrose-utilizing isolates $\left(\mathrm{Scr}^{+}\right)$, but the genetic basis of this variable phenotype remains uncharacterized. Here, we carried out the genome sequencing of five $\mathrm{Scr}^{+}$and two Scr${ }^{-} \mathrm{Pdd}$ isolates and conducted a comparative genomics analysis with sixteen additional $P d d$ genomes sequenced in previous studies. We identified two different versions of a four-gene cluster (scr cluster) exclusive of $\mathrm{Scr}^{+}$isolates encoding a PTS system sucrose-specific IIBC component (scrA), a fructokinase (scrK), a sucrose-6-phosphate hydrolase ( $s c r B)$, and a sucrose operon repressor (scrR). A scrA deletion mutant did not ferment sucrose and was impaired for growth with sucrose as carbon source. Comparative genomics analyses suggested that $s c r$ clusters were acquired by horizontal transfer by different lineages of $P d d$ and were inserted into a recombination hot-spot in the $P d d$ genome. The incongruence of phylogenies based on housekeeping genes and on scr genes revealed that phylogenetically diverse gene clusters for sucrose utilization have undergone extensive horizontal transfer among species of Vibrio and Photobacterium.
\end{abstract}

Keywords: sucrose; Photobacterium damselae; Vibrio; Vibrio damsela; TCBS; PTS; horizontal gene transfer

\section{Introduction}

The family Vibrionaceae includes a diverse and large number of bacterial species that are ubiquitous in marine habitats. Some species are recognized as pathogens for marine animals and for humans [1,2]. Also, their ecological importance in aquatic ecosystems and their high genetic plasticity have fuelled a major research effort on Vibrio, Photobacterium, and other genera of this family [3-7]. Most species exhibit a rapid growth in culture and use a large variety of nutrient sources, and the considerable inter- and intraspecies variability in metabolic and nutritional patterns is explained in part by horizontal transfer of gene functions [8-11]. Historically, carbon source utilization patterns have been extensively used to differentiate species within this family, and this knowledge has inspired the development of selective and differential culture media to enrich for specific taxa and for fast discrimination of some species. The thiosulfate citrate bile-salt sucrose (TCBS) agar, is a classical medium originally developed for the isolation of Vibrio parahaemolyticus [12] and is suitable for the isolation of many Vibrio and Photobacterium species. In addition to compounds that provide selective properties, TCBS contains $2 \%$ sucrose and $\mathrm{pH}$ indicators, allowing the differentiation between sucrose fermenters that produce yellow colonies $\left(\mathrm{Scr}^{+}\right.$phenotype) and non-fermenters that produce green colonies 
(Scr- phenotype). The sucrose fermentation pattern on TCBS is a widespread taxonomic tool for species of the family Vibrionaceae [1]. However, very much as a contradiction, the genetic basis of sucrose utilization in species of this family has received scarce attention. Pioneering studies reported the cloning and characterization of sucrose utilization genes in Vibrio alginolyticus [13-16], and later studies reported some aspects on genetics of sucrose utilization in Vibrio cholerae [17-20], whereas no studies have been conducted in species of the genus Photobacterium to date.

Understanding the genetic basis for sucrose utilization in different species of the Vibrionaceae is essential to elucidate the evolutionary history of the acquisition of this metabolic capability. Sucrose utilization ability exhibits interspecies and intraspecies variability within this family which suggests that sucrose utilization genes are prone to be acquired by horizontal gene transfer. However, the phylogenetic relationships of genes for sucrose metabolism among Photobacterium and Vibrio species has not been analyzed so far. In addition, much remains to be learned about the role of sucrose utilization genes in the ecology of Vibrios. Sucrose, a disaccharide of glucose and fructose, is one of the most abundant sugars in terrestrial environments and a carbon source used by many bacterial taxa [21]. However, the availability of sucrose in marine environments has received little attention, and of what use is sucrose utilization in the marine environment for bacteria is a question that remains largely unanswered.

The marine pathogen Photobacterium damselae subsp. damselae (hereafter Pdd), formerly known as Vibrio damsela, is a member of the family Vibrionaceae that thrives in marine and estuarine environments and is a generalist pathogen that causes high financial losses in cultures of marine fish and crustaceans [22]. Moreover, it can cause opportunistic infections in humans that may evolve into a fatal outcome [23]. Pdd is considered a genetically diverse subspecies, and horizontal gene transfer largely contributes to the generation of such diversity [22,24-26]. Pdd typically forms green colonies on TCBS medium, but early studies pointed out that $5 \%$ of the isolates produced yellow colonies on TCBS [27]. Since then, a number of studies have described Pdd strains that produce yellow colonies on TCBS [24,28-31], but the genetic basis of such phenotypic variability remains uncharacterized.

In the present study, we accomplished the de novo genome sequencing of 7 Pdd isolates, 5 that tested positive for sucrose utilization, and 2 strains that were negative for this trait. Retrieval of additional 16 Pdd genome sequences from GenBank database allowed us to conduct an extensive comparative genomics analysis of $\mathrm{Scr}^{+}$and Scr${ }^{-}$isolates that unveiled the presence of two distinct genetic variants of a four-gene cluster ( $s c r$ cluster) that is necessary for sucrose utilization as a carbon source in Pdd. Notably, the majority of the scr clusters appear to be inserted into a hot-spot for recombination of variable DNA sequences within the Pdd genome. Based on the phylogenetic analyses of the scr clusters of $P d d$ and other species of the family Vibrionaceae, and on the reconstruction of species phylogenies by using the sequences of eight conserved housekeeping genes, we propose that sucrose utilization in $P d d$ arose from the horizontal acquisition by different $P d d$ lineages, of at least two distinct versions of gene clusters from species of the Vibrio and Photobacterium genera. It is also proposed that the exchange of $s c r$ clusters among species of the family Vibrionaceae has been extensive.

\section{Materials and Methods}

\subsection{Bacterial Strains, Plasmids, and Culture Conditions}

$P d d$ strains used here are described in Table 1. Genetically-modified Pdd strains, Escherichia coli strains, and plasmids used and constructed in this study are described in Table 2. Pdd cells were routinely grown at $25^{\circ} \mathrm{C}$ on tryptic soy agar and broth supplemented with $1 \% \mathrm{NaCl}$ (TSA-1 and TSB-1, respectively), supplemented with antibiotics when appropriate. E. coli strains were routinely grown at $37^{\circ} \mathrm{C}$ in LB broth and LB agar supplemented with antibiotics when appropriate. Antibiotics were used at the following final concentrations: Kanamycin $(\mathrm{Km})$ at $50 \mu \mathrm{g} \mathrm{mL} L^{-1}$, ampicillin at $50 \mu \mathrm{g} \mathrm{mL}{ }^{-1}$, and gentamicin at $15 \mu \mathrm{g} \mathrm{mL}{ }^{-1}$. For sucrose fermentation phenotypical tests, $P d d$ strains were grown on TSA-1 plates overnight at $25^{\circ} \mathrm{C}$, and isolated colonies were seeded on thiosulfate-citrate-bile salts-sucrose agar plates (TCBS) and incubated at $25^{\circ} \mathrm{C}$ for 18-24 h. Alternatively, API-20E galleries (Biomérieux, Marcy l’Etoile, France) were used for sucrose fermentation assays, following manufacturer's recommendations. 
Table 1. General information, and results of the phenotypic tests for sucrose utilization and of PCR detection of scr genes, for the 36 Pdd strains used in this study.

\begin{tabular}{|c|c|c|c|c|c|c|}
\hline Strain & Isolation Source & Strain Reference & Scr Phenotype ${ }^{a}$ & $\begin{array}{c}\text { Presence of Sucrose } \\
\text { Genes } b\end{array}$ & Genbank Acc. No. ${ }^{c}$ & Genome Reference \\
\hline 154dp-OG1 & European sea bass, Turkey & [30] & - & - & NA & NA \\
\hline 164dp-OG2 & European sea bass, Turkey & [30] & - & - & VAUU00000000 & [26] \\
\hline 144bp-OG3 & European sea bass, Turkey & [30] & - & - & VAND00000000 & [26] \\
\hline 162bp-OG4A & European sea bass, Turkey & [30] & + & + & JABWTP000000000 & This study \\
\hline 158dp-OG5 & European sea bass, Turkey & [30] & - & - & $\mathrm{NA}$ & $\mathrm{NA}$ \\
\hline 189bp-OG7B & European sea bass, Turkey & [30] & + & + & JABXOP000000000 & This study \\
\hline 82dy-OG8 & European sea bass, Turkey & [30] & - & - & JABXOQ000000000 & This study \\
\hline 64bp-OG9 & European sea bass, Turkey & {$[30]$} & + & + & VANE00000000 & {$[26]$} \\
\hline 156dp-OG10A & European sea bass, Turkey & [30] & - & - & NA & NA \\
\hline 125dy-OG11 & European sea bass, Turkey & [30] & + & + & JACFTX000000000 & This study \\
\hline 70dps-OG12 & European sea bass, Turkey & [30] & + & + & VANF00000000 & {$[26]$} \\
\hline 164dpbuy-OG13B & European sea bass, Turkey & [30] & - & - & NA & $\mathrm{NA}$ \\
\hline 111bp-OG15A & European sea bass, Turkey & [30] & - & - & VANG00000000 & {$[26]$} \\
\hline 89dp-OG16 & European sea bass, Turkey & [30] & + & + & VANH00000000 & [26] \\
\hline CIP 102761 & Damselfish, United Estates & [32] & - & - & ADBS00000000 & Unpublished \\
\hline TW250/03 & Gilthead seabream & Laboratory collection & + & + & JABXOR000000000 & This study \\
\hline RM-71 & Turbot, Spain & [33] & - & - & LYBT00000000 & [34] \\
\hline A-162 & Eel, Belgium & $\mathrm{NA}$ & - & - & LZFN00000000 & [34] \\
\hline LD-07 & Gilthead seabream, Spain & [35] & - & - & LYBU00000000 & [34] \\
\hline DK2 & Rainbow trout, Denmark & {$[24,36]$} & - & - & PVXF00000000 & [24] \\
\hline DK3 & Rainbow trout, Denmark & {$[24,36]$} & - & - & PVXG00000000 & [24] \\
\hline
\end{tabular}


Table 1. Cont

\begin{tabular}{|c|c|c|c|c|c|c|}
\hline Strain & Isolation Source & Strain Reference & Scr Phenotype ${ }^{a}$ & $\begin{array}{c}\text { Presence of Sucrose } \\
\text { Genes } b\end{array}$ & Genbank Acc. No. ${ }^{c}$ & Genome Reference \\
\hline DK20 & Rainbow trout, Denmark & {$[24,37]$} & - & - & PVXH00000000 & {$[24]$} \\
\hline DK29 & Rainbow trout, Denmark & {$[24,37]$} & - & - & PVXI00000000 & [24] \\
\hline DK32 & Rainbow trout, Denmark & {$[24,37]$} & + & + & JABWTO000000000 & This study \\
\hline CDC-1421-81 & Fish, Senegal & [38] & - & - & JABXYE000000000 & This study \\
\hline RG-191 & Turbot, Spain & [33] & - & - & NA & NA \\
\hline ATCC35083 & Brown shark, United States & [39] & - & - & NA & NA \\
\hline CDC-2227-81 & Human, United States & [38] & - & - & VZUQ00000000 & [40] \\
\hline 80077637 & Human, Australia & [23] & - & - & WAEO00000000 & [40] \\
\hline ACRP-72.1 & Turbot, Portugal & Laboratory collection & - & - & NA & NA \\
\hline DLC 1.2 & Gilthead seabream, Spain & Laboratory collection & - & - & $\mathrm{NA}$ & NA \\
\hline DLC 4.1 & Gilthead seabream, Spain & Laboratory collection & - & - & $\mathrm{NA}$ & NA \\
\hline DLC 7.1 & Gilthead seabream, Spain & Laboratory collection & - & - & $\mathrm{NA}$ & NA \\
\hline DLC 7.3 & Gilthead seabream, Spain & Laboratory collection & - & - & $\mathrm{NA}$ & NA \\
\hline DLC 8.1 & Gilthead seabream, Spain & Laboratory collection & - & - & NA & NA \\
\hline DLC 9.1 & Gilthead seabream, Spain & Laboratory collection & - & - & NA & NA \\
\hline
\end{tabular}

a Scr phenotype evaluated by growth on TCBS agar: +, Sucrose degrading strain producing yellow colonies on TCBS; -, non-sucrose degrading strain producing green colonies. ${ }^{\mathrm{b}}$ Presence of scr cluster genes for those strains whose genome sequence is not available was assessed by PCR. ' NA: Not available. 
Table 2. Strains and plasmids used and constructed in this study.

\begin{tabular}{|c|c|c|}
\hline Strain or Plasmid & Description $^{\text {a }}$ & Reference/Source \\
\hline \multicolumn{3}{|c|}{$\begin{array}{l}\text { Strains } \\
\text { P. damselae subsp. damselae }\end{array}$} \\
\hline DK32 & Isolated from rainbow trout; ferments sucrose $\left(\mathrm{Scr}^{+}\right)$ & {$[24,37]$} \\
\hline SSS165 & DK32 $\Delta s c r A$. Does not ferment sucrose $\left(\mathrm{Scr}^{-}\right)$ & This study \\
\hline SSS250 & DK32 with plasmid pSSS250 & This study \\
\hline \multicolumn{3}{|l|}{ E. coli } \\
\hline $\mathrm{DH} 5 \alpha$ & Cloning strain & Laboratory stock \\
\hline 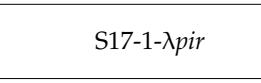 & $\begin{array}{c}\text { RP4-2(Km::Tn7, Tc::Mu-1) pro-82 } \text { pir recA1 endA1 thiE1 } \\
\text { hsdR17 creC510 }\end{array}$ & [41] \\
\hline $\begin{array}{l}\text { Plasmids } \\
\text { pHRP309 }\end{array}$ & lac Z reporter plasmid, $m o b \mathrm{Gm}^{\mathrm{r}}$ & [42] \\
\hline pSSS250 & $\begin{array}{l}\text { pHRP309 with a transcriptional fusion of } s c r A \text { promoter } \\
\text { to lacZ }\end{array}$ & This study \\
\hline pWKS30 & Low-copy-number cloning vector; $\mathrm{Ap}^{\mathrm{r}}$ & [43] \\
\hline pNidKan & Suicide vector derived from $\mathrm{pCVD} 442 ; \mathrm{Km}^{\mathrm{r}}$ & [44] \\
\hline
\end{tabular}

\subsection{PCR Assays}

All primers used in this study are described in Table 3. For PCR template preparation, isolated single colonies of each strain were picked with sterile tips, resuspended in $20 \mu \mathrm{L}$ sterile water, and $1 \mu \mathrm{L}$ suspension was added as template to the PCR tube containing the NZYTaq II $2 \times$ green master mix (NZYTech, Lisbon, Portugal), followed by a cell lysis and denaturation step of 5 min at $95^{\circ} \mathrm{C}$. PCR conditions were standardized as follows: $94{ }^{\circ} \mathrm{C}$ denaturation for $30 \mathrm{~s}$, primer annealing at $56{ }^{\circ} \mathrm{C}$ for $30 \mathrm{~s}$, elongation at $72{ }^{\circ} \mathrm{C}$ for $30 \mathrm{~s}$ per kilobase. After 30 cycles of amplification, a final elongation step at $72{ }^{\circ} \mathrm{C}$ for $1 \mathrm{~min}$ was added.

Table 3. Primer pair combinations used in this study.

\begin{tabular}{|c|c|c|}
\hline Name of Primer Pair & Oligonucleotide Sequence $^{1}$ & Amplicon Size (bp) \\
\hline scrA-1-2 & $\begin{array}{l}\text { F: 5'-GCTCTAGAGCCATTCGCACAACACTTTG-3' } \\
\text { R: 5'-GCGGATCCGTTCGCTAGATCAGTCAATC-3' }\end{array}$ & 2106 \\
\hline scrA-3-4 & $\begin{array}{l}\text { F: 5'-GC } \overline{\text { GGATCCTCAAGGTGCTGCCGCTTTAG-3' }} \\
\text { R: 5'-GCGAATTCAGGACCTTTATGCTGCCACG-3' }\end{array}$ & 2122 \\
\hline scrA-mutant-test & $\begin{array}{l}\text { F: 5'-GGCTCAGGCATAGTAAACCA-3' } \\
\text { R: 5'-CCGCGATAAATGGGTAACGT-3' }\end{array}$ & 1024 \\
\hline scrA-promoter & $\begin{array}{l}\text { F: 5'-GCTCTAGAACATCATGCAGACTCGCCAT-3' } \\
\text { R: 5'-GCGGATCCCTCTTTAGCTACTGCCGGAT-3' }\end{array}$ & 281 \\
\hline scrK & $\begin{array}{l}\text { F: 5'-TTACGCGACTCACCTCGACA-3' } \\
\text { R: } 5^{\prime} \text {-ATCGGTCGCGCAGAACAAAC-3' }\end{array}$ & 373 \\
\hline & $\begin{array}{l}\text { F: 5'-GACCAAGACTACGATTCACA-3' } \\
\text { R: 5'-ACACTCCCACATGTACCCAA-3' }\end{array}$ & 372 \\
\hline
\end{tabular}

\subsection{Genome Sequencing}

The draft genome sequences of $5 \mathrm{Scr}^{+}$(DK32, TW250/03, 162bp-OG4A, 189bp-OG7B and 125dy-OG11) and of $2 \mathrm{Scr}^{-}$Pdd strains (CDC-1421-81 and 82dy-OG8) were determined in the present study. High-purity genomic DNA was extracted using the G NOME DNA Kit (MPBio, Irvine, CA, USA). For sequencing libraries preparation, purified DNA was mechanically sheared using an ultrasonicator (Covaris Ltd., Brighton, UK), ends were enzymatically repaired and adaptors (Illumina, San Diego, CA, USA) were ligated. Libraries were sequenced using Illumina MiSeq platform $(2 \times 150$-bp paired-end reads). The reads were assembled with SPAdes 3.6 [45]. Genomes were annotated using the NCBI Prokaryotic Genome Annotation Pipeline [46]. 


\subsection{Construction of a scrA Mutant in Pdd DK32}

A nonpolar deletion of the $s c r A$ gene was constructed in the $\mathrm{Scr}^{+} P d d$ parental strain DK32 using PCR amplification of the ca. $2000 \mathrm{bp}$ sequences upstream and downstream the $s c r A$ coding sequence, which, when fused together, would result in an in-frame deletion of more than $90 \%$ of the coding sequence. Amplification was carried out with primer pair scrA 1-2 to get the $5^{\prime}$ fragment, and with primer pair scrA 3-4 to get the $3^{\prime}$ fragment (Table 3). The PCR products were cut with suitable restriction enzymes and sequentially ligated into the multiple cloning site of pKWS30 plasmid. This cloned fragment involving the deleted region was excised with NotI and ApaI and then ligated into the $\mathrm{Km}^{\mathrm{r}}$ suicide vector pNidKan containing the $s a c B$ gene, which confers sucrose sensitivity, and R6K ori, which requires the pir gene product for replication. The pNidKan plasmid construct containing the deleted allele was transferred from E. coli S17-1- $\lambda$ pir into parental Pdd strain DK32. After conjugation for $48 \mathrm{~h}$ on TSA plates prepared with seawater, cells were scrapped off the plate and suspended in TSB-1. Next, $100 \mu \mathrm{L}$ aliquots of serial decimal dilutions were spread on TCBS agar supplemented with kanamycin to select for $P d d$ clones that have undergone a first recombination event, as growth of $E$. coli donors is inhibited on TCBS agar. Insertion of the suicide vector into the Pdd genome by homologous recombination results in kanamycin resistance, and in sucrose sensitivity due to $s a c B$ gene. Kanamycin resistant colonies were subsequently cultured in TSB-1 without antibiotic selection, and serial decimal dilutions were spread on TSA-1 plates supplemented with sucrose $(15 \%(\mathrm{wt} / \mathrm{vol}))$ to select for a second recombination event. Reisolated colonies were tested by PCR using primer pair scrA-mutant-test (Table 3) to identify recombinants in which the mutant allele of the $s c r A$ gene replaced the parental allele. This led to mutant strain DK32 $\Delta s c r A$ (SSS165) (Table 2).

\subsection{Growth Assays with Sucrose as a Carbon Source}

Parental DK32, and DK32 $\Delta s c r A$ strain were streaked on a TSA-1 plate and incubated overnight at $25^{\circ} \mathrm{C}$. A loopful of cells was resuspended in phosphate buffered saline (PBS) to achieve an optical density of 0.3 at $600 \mathrm{~nm}\left(\mathrm{OD}_{600}: 0.3\right)$. For the assay, $1 \mu \mathrm{L}$ of the bacterial cell suspensions was aliquoted into the wells of a 96-well plate containing $100 \mu \mathrm{L}$ of $\mathrm{M} 9$ minimal medium [47] supplemented, when necessary, with $0.2 \%$ (wt/vol) Casamino Acids (Thermo Fisher Scientific Inc, Waltham, MA, USA) (CM9), and with a sugar $(0.5 \%$ glucose or $2 \%$ sucrose $(\mathrm{wt} / \mathrm{vol}))$ depending on the aim of the experiment. Final concentration of $\mathrm{NaCl}$ was adjusted to $1 \%$ in all the assays. For each assay, $\mathrm{OD}_{600}$ values were recorded every $10 \mathrm{~min}$ for $20 \mathrm{~h}$. This experiment was automated using the spectrophotometer Epoch2 microplate reader (BioTek, Winooski, VT, USA). The 96-well plates were continuously incubated at $25^{\circ} \mathrm{C}$ in the plate reader with shaking. Three replicates were performed per assayed condition and strain. Mean values are reported and error bars represent the standard deviations.

\subsection{Construction of a Transcriptional Fusion of scrA Promoter to a lacZ Reporter Gene, and $\beta$-Galactosidase Assays}

The putative scr A gene promoter was PCR amplified with primer pair scrA-promoter (Table 3) and fused to a promotorless lacZ gene in the low-copy-number reporter plasmid pHRP309. The plasmid with the transcriptional fusion construct pscrA::lacZ (pSSS250), was mobilized from E. coli S17-1- $\lambda$ pir into $P d d$ parental strain DK32 by conjugation. After conjugation for $24 \mathrm{~h}$ on TSA plates prepared with seawater, cells were scrapped off the plate, suspended in TSB-1, and $100 \mu \mathrm{L}$ aliquots of serial decimal dilutions were spread on TCBS agar supplemented with gentamicin (resistance provided by pHRP309). DK32 transformants harboring pSSS250 plasmid (DK32 pscrA::lacZ) were grown in CM9 medium supplemented either with $1 \%$ glucose or with $1 \%$ sucrose, and $\beta$-galactosidase activities were measured as previously described and expressed in Miller units [48]. Three independent experiments with 3 replicates each were conducted. Mean values are reported and error bars represent the standard deviations. The statistical analysis of the gene expression data was carried out with Mann-Whitney test. 


\subsection{Comparative Genomics and Molecular Phylogeny Analyses}

Comparative genomics analysis to search for genes specific of Scr+ strains was conducted with RAST [49]. Pfam database was used for predictions of protein domains [50]. Easyfig v.2.2.3. [51], was used for comparative analysis and visualization of gene architecture of scr clusters of Photobacterium and Vibrio species. The Genbank accession numbers of Vibrio and Photobacterium genomes used in the comparative genomics and in the phylogenetic analyses are listed in Table 4. A phylogenetic tree of $23 P d d$ complete genomes was constructed using the guide tree obtained by MAUVE genome alignment program (progressive Mauve option) [52,53].

Table 4. GenBank accession numbers of the Vibrio and Photobacterium genomes whose sucrose degrading cluster genes (scr genes) were used in the comparative genomics and phylogenetic analyses in this study.

\begin{tabular}{ll}
\hline \multicolumn{1}{c}{ Species } & \multicolumn{1}{c}{ Accession Number } \\
\hline Vibrio alfacsensis & CP032093.1 \\
V. parahaemolyticus & QPIY01000005 \\
V. alginolyticus & AAPS01000004 \\
Vibrio rotiferianus & NZ_KV861318 \\
Vibrio diabolicus & CP014133 \\
Vibrio harveyi & CP014038 \\
Vibrio fortis & NZ_JFFR01000009 \\
Vibrio cyclitrophicus & VUKB01000001 \\
Photobacterium lutimaris & NZ_SNZO01000003 \\
Vibrio crassostreae & NZ_AJZB02000137 \\
Photobacterium angustum & NZ_PYOK01000006 \\
Photobacterium frigidiphilum & NZ_PYMJ01000001 \\
Photobacterium profundum & NZ_PYOD01000001 \\
Photobacterium indicum & NZ_PYOC01000002 \\
V. cholerae & NZ_VTLI01000001 \\
Photobacterium halotolerans & NZ_AULG01000013 \\
Photobacterium rosenbergii & NZ_PYMB01000001 \\
Photobacterium lipolyticum & NZ_PYMC01000002 \\
\hline
\end{tabular}

The species tree was generated using the concatenated amino acid sequences of the proteins encoded by 8 housekeeping genes, ftsZ (cell division protein FtsZ), gapA (glyceraldehyde 3-phosphate dehydrogenase), gyrB (DNA gyrase subunit B), $m r e B$ (rod shape-determining protein MreB), rec $A$ (RecA recombinase $\mathrm{A}$ ), $p y r H$ (uridylate kinase, uridine monophosphate kinase), top $A$ (DNA topoisomerase I), and toxR (transmembrane transcription regulator). These housekeeping sequences were selected on the basis of their demonstrated value for fine-tuned discrimination of taxa within the family Vibrionaceae $[9,54,55]$. The sucrose genes tree was constructed using the concatenated amino acid sequences of the proteins encoded by the 4 sucrose cluster genes scrRAKB. The Mesquite 3.61 program was used to concatenate the protein sequences [56].

Evolutionary analyses were conducted in MEGA X [57]. The evolutionary history of the strains was inferred using the Neighbor-Joining method [58]. The percentage of replicate trees in which the associated taxa clustered together in the bootstrap test (1000 replicates) is shown next to the branches. The evolutionary distances were computed using the Maximum Composite Likelihood method [59], and are in the units of the number of base substitutions per site.

\subsection{Database Submission}

The draft genome sequences of the $7 P d d$ strains determined in this study are available from Genbank under accession numbers listed in Table 5. 


\section{Results}

3.1. Identification of Two Different Genetic Variants of a Four Gene Cluster Encoding Functions for Sucrose Uptake and Catabolism in Pdd Strains

In order to study sucrose utilization in this marine pathogen, we screened a collection of $36 P d d$ isolates from diverse geographical origins and isolation sources, for their ability to utilize sucrose on the selective and differential medium TCBS. This screening revealed that 8 strains grew as yellow colonies, thus exhibiting a Scr${ }^{+}$phenotype (Figure 1a; Table 1). To gain an insight into the genetic basis of sucrose utilization, we here obtained the de novo genome sequences of $5 \mathrm{Scr}^{+}$strains, namely DK32, TW250/03, 162bp-OG4A, 189bp-OG7B and 125dy-OG11, and 2 Scr $^{-}$Pdd isolates, CDC-1421-81 and 82dy-OG8. The general features of the $7 \mathrm{Pdd}$ genomes sequenced in the present study are described in Table 5. In addition, we retrieved from GenBank database the genomes of $3 \mathrm{Scr}^{+}$strains (64bp-OG9, 70dps-OG12, and 89dp-OG16) that have been sequenced in our laboratory in a recent study focused on the presence of large multidrug resistance plasmids in this subspecies [26] (Table 1), as well as 13 genomes of $\mathrm{Scr}^{-} P d d$ strains obtained in previous studies in our laboratory (Table 1). Pdd genomes were compared using RAST tool [49], searching for genes present in Scr ${ }^{+}$strains and absent from Scr strains. Interestingly, the comparative genomics analysis unveiled two distinct versions of a 4-gene $s c r$ cluster, and the versions differed in their nucleotide sequence in a 30\% (Figure 2). The majority version, hereafter version 1, was present in all the $\mathrm{Scr}^{+}$strains except in OG12, that contained the version 2 of the cluster instead. The locus tags of the four genes comprising the scr cluster in each of the $8 \mathrm{Scr}^{+}$ genomes are detailed in Table 6. These genes were organized in two divergently transcribed putative operons (Figures $1 \mathrm{~b}$ and 2). On the one side, scrR encodes a putative sucrose operon repressor of the LacI family. The other three genes are transcribed from the opposite strand, and encode, based on their similarity to the $V$. alginolyticus and $V$. cholerae sucrose utilization genes, a PTS system sucrose-specific IIBC component (EC 2.7.1.211) (scrA), a fructokinase (EC 2.7.1.4) (scrK), and a sucrose-6-phosphate hydrolase (EC 3.2.1.26) (scrB), respectively [14-16,18]. 


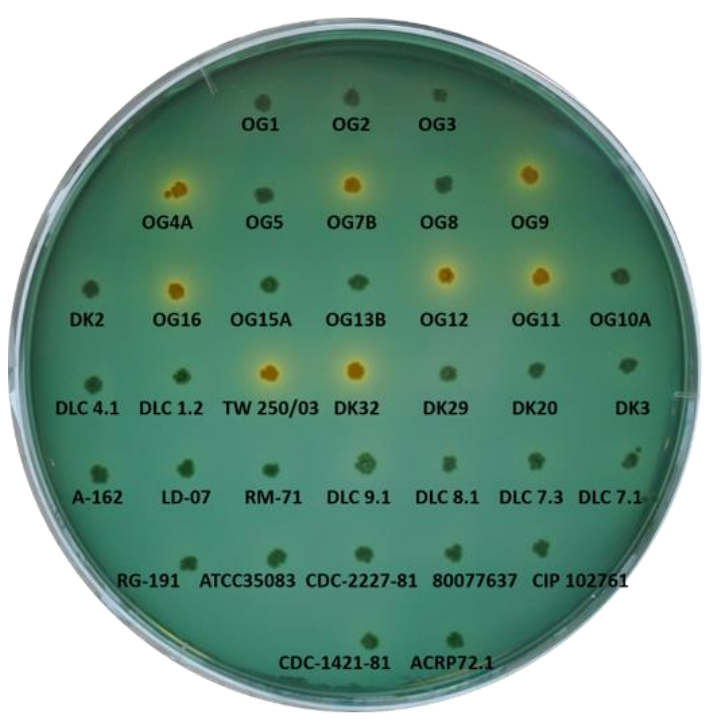

(a)

DK32

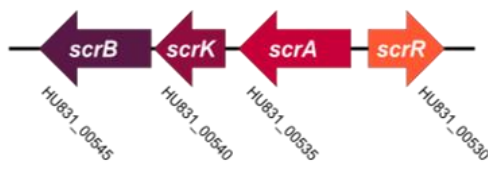

Sucrose cluster:

scrB: Sucrose-6-phosphate hydrolase

scrk: Fructokinase

scrA: PTS system, sucrose-specific IIBC components

scrR: Sucrose operon repressor

(b)

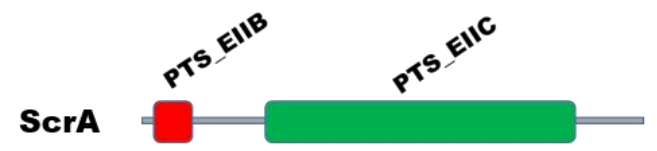

(c)

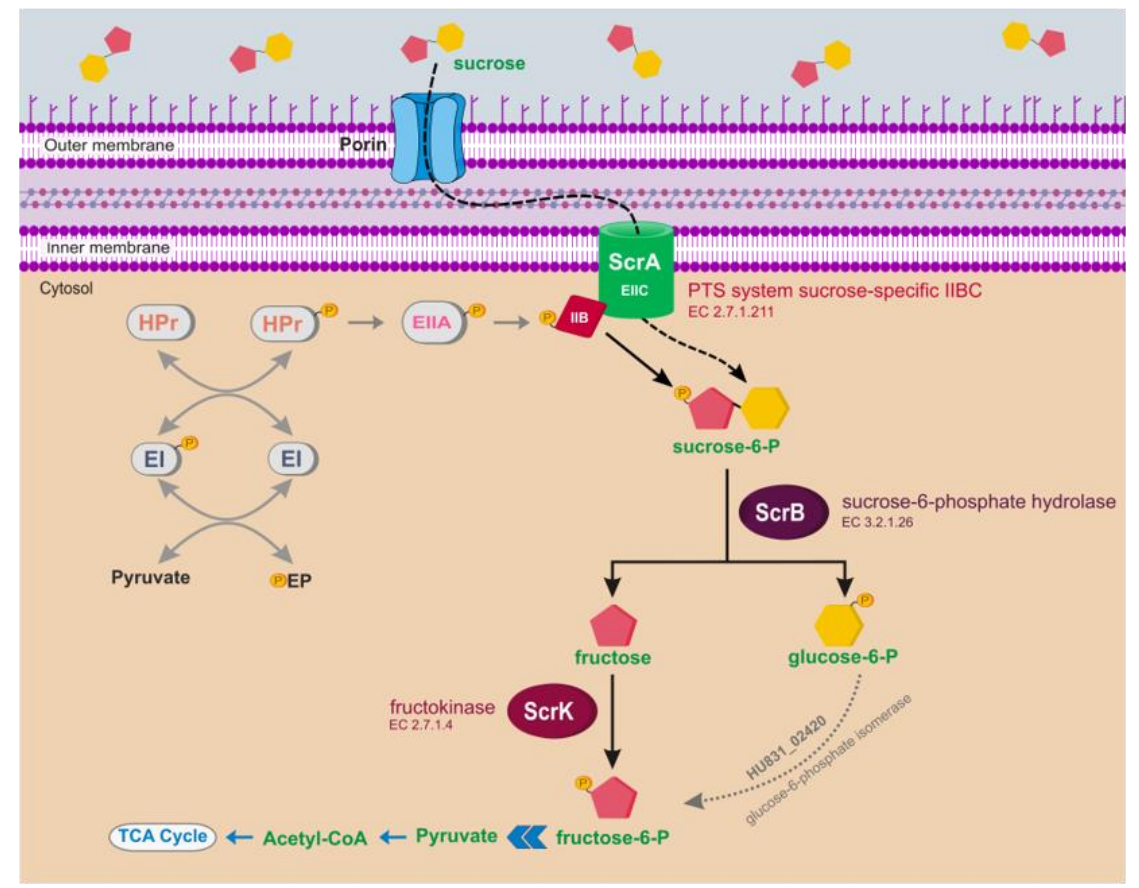

(d)

Figure 1. (a) Sucrose fermentation phenotypes of $36 P d d$ strains cultured on thiosulfate-citrate-bile salts-sucrose agar plates (TCBS) agar. Sucrose-fermenting strains $\left(\mathrm{Scr}^{+}\right)$form yellow colonies whereas non-sucrose fermenters $\left(\mathrm{Scr}^{-}\right)$form green colonies; (b) scr cluster of Pdd strain DK32 identified in this study, depicting the conserved gene architecture in this subspecies; (c) Pfam domain prediction for the Pdd ScrA protein, showing the presence of the two domains PTS_EIIB and PTS_EIIC within the same protein; (d) A model for sucrose utilization pathway in $P d d$. 




Figure 2. Representation of the $s c r$ clusters identified in the eight sucrose-degrading $P d d$ strains characterized in the present study, depicting the majority version 1, and the version 2 unique to strain 70dps-OG12. The nucleotide sequence of the cluster of strain 70dps-OG12 differs in 30\% from the clusters of the other 7 strains. The genetic context revealed to be highly conserved in 5 out of the 8 strains, with some differences in the context of DK32. For 70dps-OG12 and TW250/03 the flanking regions could not be identified with precision due to difficulties in draft genome assembly, likely motivated by the existence of repeated sequenced regions. With the exception of 70dps-OG12, we identified a duplicated 13-mer sequence (TTTATAAAAAGGG) flanking the scr cluster in all the strains, that is denoted by vertical green bars. 
Table 5. General features of the $7 P d d$ genomes sequenced in this study.

\begin{tabular}{|c|c|c|c|c|c|c|c|}
\hline Attribute & 162bp-OG4A $\left(\mathrm{Scr}^{+}\right)$ & 189bp-OG7B $\left(\mathrm{Scr}^{+}\right)$ & 82dy-OG8 $\left(\mathrm{Scr}^{-}\right)$ & 125dy-OG11 $\left(\mathrm{Scr}^{+}\right)$ & DK32 $\left(\mathrm{Scr}^{+}\right)$ & TW250/03 $\left(\mathrm{Scr}^{+}\right)$ & CDC-1421-81 (Scr- $)$ \\
\hline Accession no. & JABWTP000000000 & JABXOP000000000 & JABXOQ000000000 & JACFTX000000000 & JABWTO000000000 & JABXOR000000000 & JABXYE000000000 \\
\hline Genome size (bp) & $4,306,101 \mathrm{bp}$ & $4,302,857 \mathrm{bp}$ & $4,627,325 \mathrm{bp}$ & $4,450,948 \mathrm{bp}$ & $4,248,331 \mathrm{bp}$ & $4,695,503 \mathrm{bp}$ & $4,432,211 \mathrm{bp}$ \\
\hline Contigs & 133 & 127 & 138 & 147 & 106 & 1649 & 81 \\
\hline$\%$ GC & $40.70 \%$ & $40.70 \%$ & $40.70 \%$ & $40.70 \%$ & $40.60 \%$ & $39.80 \%$ & $40.40 \%$ \\
\hline CDSs & 3756 & 3758 & 4038 & 3879 & 3699 & 5041 & 3860 \\
\hline
\end{tabular}

Table 6. Locus tags of the $s c r$ gene clusters in the $8 \mathrm{Scr}^{+} P d d$ genomes analyzed in this study.

\begin{tabular}{|c|c|c|c|c|c|c|c|c|}
\hline Strain & 162bp-OG4A & 189bp-OG7B & $64 \mathrm{bp}-\mathrm{OG} 9$ & 125dy-OG11 & 70dps-OG12 & 89dp-OG16 & DK32 & TW250/03 \\
\hline Accession no. & JABWTP000000000 & JABXOР000000000 & VANE00000000 & JACFTX000000000 & VANF00000000 & VANH00000000 & JABWTO000000000 & JABXOR000000000 \\
\hline \multicolumn{9}{|c|}{ Sucrose operon genes (locus_tag) } \\
\hline scr $A$ & HU985_14400 & HVV26_09235 & FD719_10830 & H3N34_00965 & FD720_04185 & FD722_11585 & HU831_00535 & HWA77_17195 \\
\hline $\operatorname{scr} B$ & HU985_14390 & HVV26_09225 & FD719_10820 & H3N34_00955 & FD720_04175 & FD722_11575 & HU831_00545 & HWA77_17185 \\
\hline scrK & HU985_14395 & HVV26_09230 & FD719_10825 & H3N34_00960 & FD720_04180 & FD722_11580 & HU831_00540 & HWA77_17190 \\
\hline $\operatorname{scr} R$ & HU985_14405 & HVV26_09240 & FD719_10835 & H3N34_00970 & FD720_04190 & FD722_11590 & HU831_00530 & HWA77_17200 \\
\hline
\end{tabular}


Protein domain predictions by Pfam database, and similarity search analysis by BLAST, indicated that the Pdd scrA gene encodes a EIIBC-domain containing protein, of the phosphoenolpyruvate-dependent phosphotransferase system (PTS) (Figure 1c). According to the in silico analysis of these four genes and their predicted protein products, it is hypothesized that Pdd utilizes sucrose via the PTS mechanism, following the scheme depicted in Figure 1d. The conserved PTS system is one of the most common mechanisms for high affinity uptake of sugars in bacteria. It consists of a phosphotransfer cascade that catalyzes the transfer of a phosphate group from phosphoenolpyruvate (PEP) to a carbohydrate substrate concomitant with its transport into the cytoplasm [60,61]. The PTS system includes three major components: Enzyme I (EI), EII (EIA-C) and the histidine-containing phosphocarrier protein (HPr). EI and HPr are shared by all PTS transporters. EI autophosphorylates in the presence of PEP and transfers the phosphate group to HPr. Subsequently, HPr passes the phosphoryl group to a sugar-specific EIIA protein, EIIA passes it to its cognate EIIB, and the latter transfers the phosphoryl group to a sugar bound to the cognate, inner membrane-spanning EIIC element, facilitating sugar import. Thus, the EII complexes consist of three domains, EIIA, EIIB, and EIIC, that can either be part of the same protein (an EIIABC protein), or can be encoded by distinct proteins. The EIIC domain defines the carbohydrate specificity within these transport systems [60]. Once sucrose is taken up by the EIIC component of ScrA, it yields intracellular sucrose-6-phosphate that is hydrolyzed to glucose-6-phosphate and fructose by the sucrose-6-phosphate hydrolase (scrB). Fructose is phosphorylated to fructose-6-phosphate by the fructokinase encoded by srcK, and the two monosaccharides would enter the glycolytic pathway (Figure 1d).

On the light of the comparative genomics of $23 P d d$ strains for which genome sequences are available (Table 1), there is a $100 \%$ correlation between presence of the scr cluster, either version 1 or version 2 , and the ability to ferment sucrose on TCBS. A previous study reported that a naturally-occurring, single nucleotide insertion in scrA gene rendered $V$. cholerae strain IEC224 unable to ferment sucrose [19]. We thus wanted to assess whether the $\mathrm{Scr}^{-}$phenotype of $P d d$ strains could be due in some instances to point mutations in the sucrose operon. To this aim we selected $13 P d d$ strains which are phenotypically $\mathrm{Scr}^{-}$and whose genome sequences are not available (Table 1), and conducted a PCR screening with two primer pairs targeted to sequences conserved in the $s c r B$ and $s c r R$ genes of the two versions of $s c r$ clusters described in this study. As a result, it was found that all the Scr${ }^{-}$isolates tested negative in the PCR tests, whereas all the Scr ${ }^{+}$strains tested positive for $s c r B$ and $s c r R$ genes (Table 1).

The genetic context upstream and downstream the scr cluster was found to be highly conserved in six of the eight $\mathrm{Scr}^{+}$strains (Figure 2), where this cluster is invariably flanked by genes encoding a YgiQ family protein (locus HU831_00550) and a hypothetical protein (locus HU831_00525) (loci tags refer to the DK32 draft genome). The gene homologous to HU831_00550 in the closed genome sequence of the Pdd type strain CIP102761 (locus VDA_001759) maps to chromosome I, which suggests that the version 1 of $s c r$ cluster is chromosome I-borne in Pdd. For strains 70dps-OG12 and TW250/3 the flanking regions could not be identified with precision due to gaps in draft genome assembly, likely caused by the existence of repeated sequences, as insertion sequence elements. In any case, the context of sucrose genes in 70dps-OG12 was unrelated to the context of the other $7 \mathrm{Scr}^{+}$strains. The observation of a highly conserved context in most $\mathrm{Scr}^{+}$strains suggest that the scr cluster was inserted into the genome by means of some mechanism of DNA recombination. Notably, a duplicated 13-mer sequence (TTTATAAAAAGGG) was found flanking both sides of the scr cluster in all the strains with the exception of 70dps-OG12 (Figure 2).

3.2. Deletion of scrA in the scr ${ }^{+}$Strain DK32 Causes Green Colonies on TCBS Medium, and Abolishes Growth with Sucrose as Carbon Source

As described above, scrA encodes a EIIBC-domain containing protein with a predicted role in sucrose utilization. In order to investigate this, a non-polar, unmarked deletion mutant for scr $A$ gene was constructed in the $P d d$ wild type strain DK32 by allelic exchange, a process that removed $90 \%$ of the $s c r A$ coding sequence without disrupting the reading frame. As a result, it was observed that DK32 
$\triangle s c r A$ produced green colonies on TCBS (Figure 3a), suggesting that this mutant is unable to transport sucrose into the cell. In addition, DK32 $\triangle s c r A$ produced a negative result for sucrose fermentation in the API-20E gallery, which is routinely used in laboratories for the identification of fish pathogenic bacteria (Figure $3 b$ ). Unexpectedly, mutation of scrA caused a change in the colony phenotype compared to the wild type colonies, when the strains were cultured on TSA- 1 supplemented with $15 \%(\mathrm{wt} / \mathrm{vol})$ sucrose, the sugar concentration used to select for a second recombination step during the allelic exchange process (see methods). DK32 wt colonies appeared flat and translucent while DK32 $\Delta s c r A$ colonies appeared convex and whitish (Figure 3c). We thus hypothesized that the presence of the sucrose fermenting gene cluster in the bacterial genome might be responsible for causing such phenotype when the strain is growing in presence of high concentrations of sucrose. In order to test this, we analyzed the colony morphologies of the naturally Scr${ }^{+}$and $\mathrm{Scr}^{-}$strains 89dp-OG16 and LD-07, respectively. Strains containing the $s c r$ cluster yielded flat and translucent colonies, whereas $\mathrm{Scr}^{-}$strains yielded convex and whitish colonies. The colony phenotypes of $\mathrm{Scr}^{+}$and $\mathrm{Scr}^{-}$strains were indistinguishable on TSA-1 without added sucrose (Supplementary Figure S1).

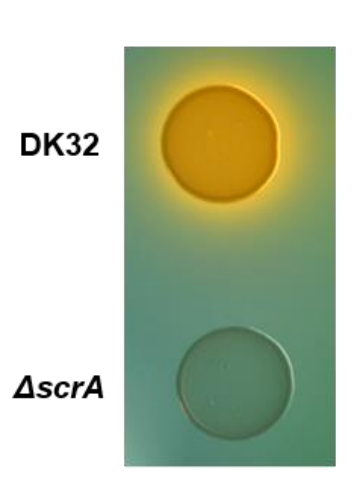

(a)

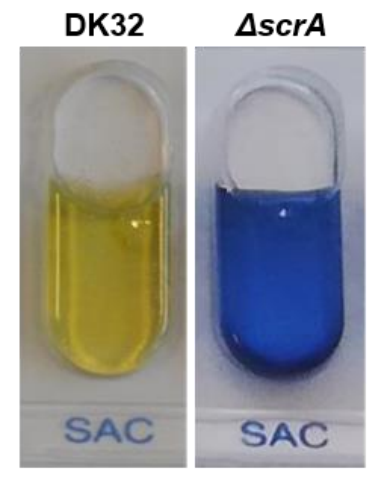

(b)

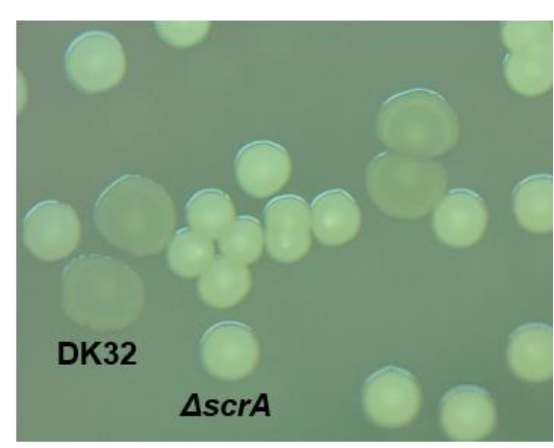

(c)

Figure 3. Phenotypical analysis of the scrA mutant in Pdd DK32. Deletion of $s c r A$ produces green colonies on TCBS agar (a), yields a negative result in the sucrose fermentation test in API-20E (b), and causes changes in colony morphology compared to the parental strain when grown on TSA agar plates supplemented with $15 \%$ sucrose (c).

We next studied how deletion of $s c r A$ impacted Pdd DK32 growth with sucrose as a carbon source. To this aim, it was first necessary to optimize the conditions for culturing Pdd in minimal medium. It is pertinent to highlight that no detectable growth was achieved neither by the parental strain nor by the $\triangle s c r A$ mutant when cultured in minimal medium M9 with glucose $0.5 \%$, suggesting that $P d d$ DK32 cannot efficiently synthesize all the necessary amino acids in a mineral minimal medium with glucose as carbon source (Figure 4a). Similarly, the minimal medium M9 supplemented with casamino acids as sole carbon source in the absence of glucose, did not support growth within $20 \mathrm{~h}$ (Figure $4 \mathrm{a}$ ), suggesting that $P d d$ does not efficiently use amino acids as carbon source, and needs a sugar for optimal growth. In support of these hypotheses, growth of DK32 and DK32 $\Delta$ scrA strains was completed to the stationary phase within $20 \mathrm{~h}$ when casamino acids were added to M9 with glucose $0.5 \%$ (CM9 medium) (Figure 4a). These results demonstrate that deletion of scrA does not cause a fitness cost in the growth of $P d d$ with glucose as carbon source in presence of casamino acids. However, when $2 \%$ sucrose was added to CM9 medium in substitution of glucose, the DK32 $\Delta s c r A$ mutant was drastically impaired for growth, whereas the parental strain achieved full growth values as with glucose (Figure $4 b$ ). 


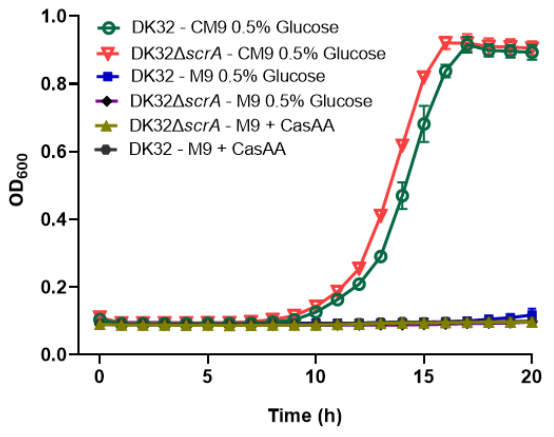

(a)

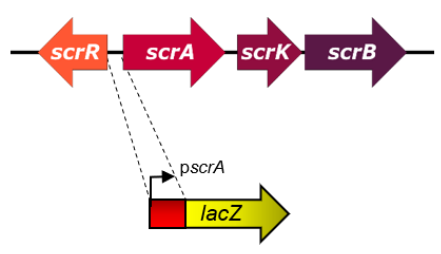

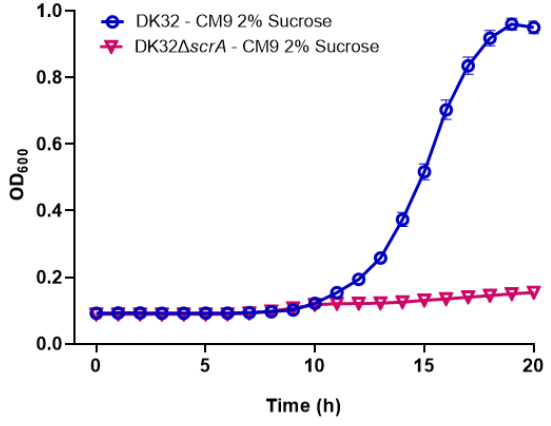

(b)

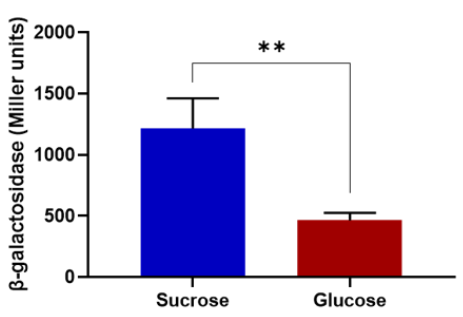

Figure 4. (a) Growth curves of $P d d \mathrm{DK} 32$ parental and $\Delta s c r A$ strains in minimal medium M9 and in M9 supplemented with casamino acids (CasAA) (CM9), with or without glucose. $P d d$ is unable to grow in minimal medium unless casamino acids and sugar (glucose) are provided. No differences in growth are detected between parental and $\Delta s c r A$ strains; (b) Substitution of $0.5 \%$ glucose by $2 \%$ sucrose in CM9 sustains growth of DK32 parental strain, whereas $\triangle s c r A$ mutant growth is abolished; (c) A transcriptional fusion of $s c r A$ promoter to a reporter lacZ gene reveals that promoter activity is 2.5 -fold upregulated when sucrose substitutes glucose as carbon source. Mean values $\pm \mathrm{SE} ; n=3 ;{ }^{* *}, p \leq 0.01$. Statistical significance was determined by an unpaired two-tailed Mann-Whitney test.

We also analyzed whether the transcriptional activity of the promoter upstream scrA was affected by growth in presence of sucrose. To this aim, the scrA promoter sequence (pscrA) was fused to a promoterless lacZ gene in plasmid pHRP309, that was further mobilized to Pdd parental strain DK32, yielding DK32 pscrA::lacZ. This indicator strain was cultured in CM9 medium supplemented with either $1 \%$ sucrose or $1 \%$ glucose. The measure of $\beta$-galactosidase activities demonstrated that $s c r A$ promoter exhibited basal transcription levels in presence of glucose as carbon, and promoter activity was increased 2.5-fold in the presence of sucrose as carbon source (Figure 4c). Collectively, the growth assay data and transcriptional fusion analysis, demonstrate that $s c r A$ is necessary for sucrose utilization as carbon source in $P d d$ and its transcription is increased in presence of sucrose.

\subsection{Scr Clusters Are Inserted into Putative Hot-Spots for DNA Acquisition in Pdd Genomes}

We hypothesized that the genome region flanked by the genes encoding the YgiQ family protein and the lysophospholipid acyltransferase, i.e., the DNA region harboring the scr cluster in the majority of $\mathrm{Scr}^{+} P d d$ strains, represents a hot-spot for events of DNA acquisition and loss. In order to gain an insight into this, we conducted a comparative analysis of the gene composition within this putative hot-spot in eleven $\mathrm{Scr}^{-} P d d$ strains, which included two strains newly sequenced in the present study (CDC-1421-81 and 82dy-OG8) and 9 additional Scr ${ }^{-}$strains whose draft genomes were retrieved from GenBank database (Table 1). We found that 70dps-OG12, the Scr ${ }^{+}$strain whose context of the scr cluster remains unknown, contained a number of hypothetical proteins and transposases in this region, and was identical to the gene composition of the homologous region in the $\mathrm{Scr}^{-}$strain 111bp-OG15A (Figure 5). Notably, analysis of the $11 \mathrm{Scr}^{-}$genomes unveiled the existence of 11 unique gene combinations, i.e., each strain contained genes with no counterparts in the other $P d d$ genomes. 
These observations provide strong evidence that this genome region is highly prone to events of DNA acquisition and can be considered as a recombination hot-spot for acquisition of DNA. Of note, the duplicated 13-mer sequence TTTATAAAAAGGG was found in most strains at exactly the same point (Figure 5).

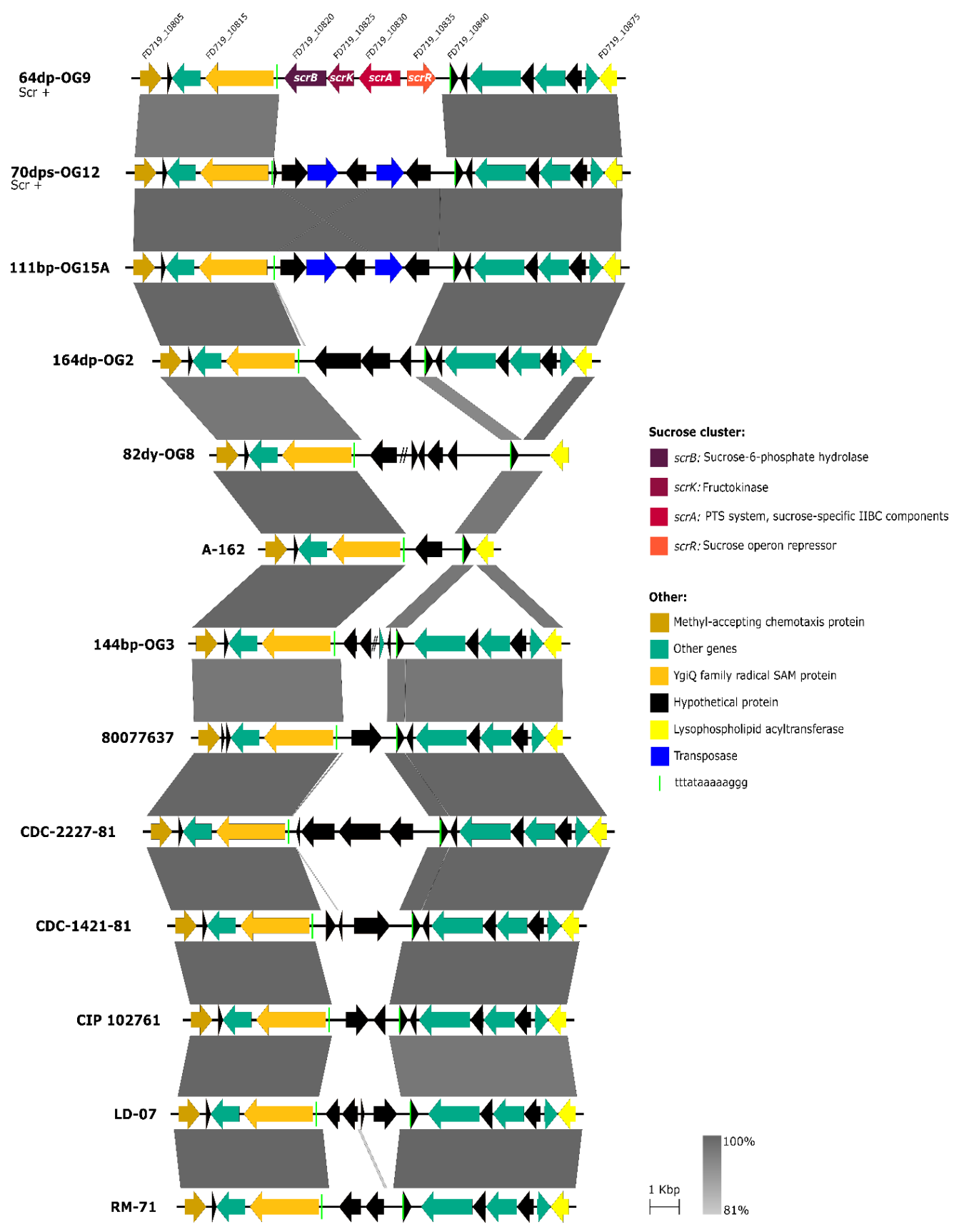

Figure 5. Version $1 P d d s c r$ clusters are inserted within a genome region that shows high genetic plasticity among $P d d$ strains. The scr cluster of strain 64bp-OG9 is shown as reference. Note that the 11 depicted Scr ${ }^{-}$strains, as well as Scr ${ }^{+}$strain 70dps-OG12 (that harbors a scr cluster in another genomic location) each contain a unique gene repertoire in this genomic region, that is proposed to be a hot-spot for recombination of horizontally acquired DNA. The variable DNA is in most cases flanked by a direct repeat of the 13-mer sequence TTTATAAAAAGGG. 


\subsection{Scr Clusters Occur in Different Genetic Lineages of Pdd}

In this study, 8 Pdd strains contained a scr gene cluster. Of these, six were isolated from European seabass in the Black Sea [30], one from diseased rainbow trout in Denmark [24,37] and one from gilthead seabream from unknown geographical origin (Table 1). In order to ascertain whether the sucrose positive strains conform a clonal entity or whether the scr clusters have been acquired by different genetic lineages of $P d d$, we carried out a comparative analysis of 23 complete $P d d$ genomes. As shown in Figure 6, five Scr${ }^{+}$strains isolated from the Black Sea group together within a clade, and among these, the pairs OG7B/OG4A and OG9/OG16 likely correspond to two clonal lines respectively. However, 125dy-OG11 is distantly related from the aforementioned four strains, and clearly represents an evolutionary line that has diverged from the other strains. Of note, the three remaining $\mathrm{Scr}^{+}$strains are unevenly distributed with other $\mathrm{Scr}^{-}$genomes in different branches of the phylogenetic tree. It is noticeable that strain DK32, isolated in the coast of Denmark in 2006, harbors a scr cluster 99.9\% identical at the nucleotide sequence level to the scr cluster of 125dy-OG11, isolated in the Black Sea in 2011, despite these two strains being distantly located in the phylogenetic tree (Figure 6). All these results provide strong evidence that the $\mathrm{Scr}^{+}$isolates are not clonal derivatives (with the exception of the pairs OG7B/OG4A and OG9/OG16), and support the hypothesis that scr clusters have been acquired by horizontal transfer by different genetic lineages of $P d d$, as a result of independent events of DNA acquisition.

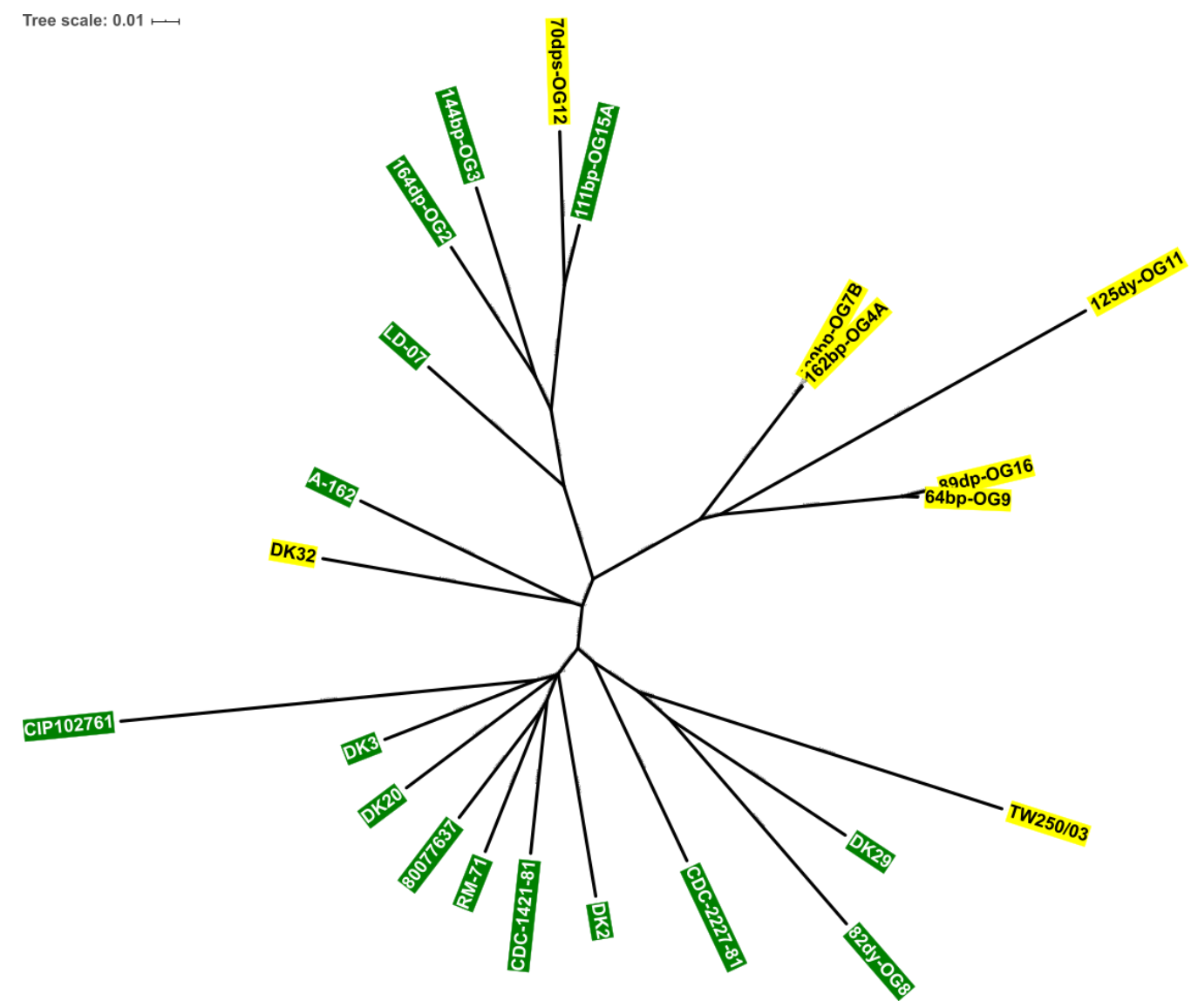

Figure 6. Dendrogram of Scr${ }^{+}$(yellow) and $\mathrm{Scr}^{-}$(green) Pdd strains based on the MAUVE genome alignment program, showing that scr clusters occur in different genetic lineages of this subspecies. 
3.5. Incongruences between the Species Tree and the Sucrose Genes Tree Reveal Extensive Horizontal Transfer of scr Genes among Species of Vibrio and Photobacterium

The high percentages of sequence identity and of operon architecture in scr cluster genes among 7 of the $8 \mathrm{Pdd}$ strains analyzed in the present study, clearly indicate a common evolutionary origin of sucrose cluster genes in these strains. In addition, the observation that the scr cluster in strain 70dps-OG12 exhibits 30\% sequence divergence with respect to the other $7 \mathrm{Pdd}$ strains, suggests that scr clusters have been gained in this subspecies by horizontal gene transfer from different donor species. Although sucrose utilization is a widespread trait in many species within the family Vibrionaceae, the phylogenetic relationships among sucrose utilization clusters from different species remains largely uncharacterized. Here, we conducted a Genbank database search to retrieve gene clusters encoding sucrose utilization genes in species of Photobacterium and Vibrio (Accession numbers are listed in Table 4) that were homologous to the Pdd clusters. A schematic analysis of the two representative Pdd clusters (64bp-OG9 and 70dps-OG12) and of 18 Photobacterium and Vibrio clusters revealed that gene architecture is largely conserved, with the exception of $V$. cholerae, P. halotolerans, P. rosenbergii, and P. lipolyticum that showed different gene arrangements (Figure 7).

In order to determine the evolutionary history of sucrose uptake and catabolism genes, we reconstructed the phylogeny of ScrB, ScrK, ScrA and ScrR proteins among Photobacterium and Vibrio species. Proteins representing homologues within these two genera were aligned using ClustalW and phylogenetic trees were constructed by the neighbor-joining method using MEGA X [57]. This analysis demonstrated that the scr genes of 7 out of the $8 P d d$ strains (version 1 cluster), are closely related to the clusters found in Vibrio species. On the contrary, the cluster of Pdd 70dps-OG12 (version 2 cluster) is related to clusters found in species of the genus Photobacterium and shares the same branch with $V$. cyclitrophicus and $V$. crassostreae (Figure 8). These observations clearly suggest that scr clusters have undergone horizontal gene transfer among species of the two genera. In order to clarify this, we conducted in parallel a phylogenetic analysis of the same Photobacterium and Vibrio species, by analyzing the concatenated amino acid sequences of eight housekeeping genes conserved in all the species, and producing a "species tree" that was compared to the "sucrose genes tree". The analysis of these housekeeping genes generated a phylogenetic tree with three distinct clades that include the $8 P d d$ strains, the rest of Photobacterium species, and the Vibrio species, respectively. The noticeable incongruence between sucrose operon tree and species tree clearly indicates that sucrose genes found in $7 \mathrm{Pdd}$ strains (version 1 cluster) are closely related to clusters of Vibrio species, being $V$. alfacsensis the closest relative, while they are more distantly related to the clusters of Photobacterium species. This suggests that $P d d$ sucrose cluster version 1 may have been acquired by $P d d$ strains from a Vibrio-like donor. The scr cluster of Pdd 70dps-OG12 (version 2) has a different evolutionary history than the other $7 \mathrm{Pdd}$ clusters, and is more similar to both Vibrio and Photobacterium clusters. Notably, the close evolutionary distance between sucrose clusters of P. lutimaris and V. crassostreae contrasts with the placement of these two species in two different clades in the species tree. All these observations provide strong evidence that horizontal gene transfer of sucrose genes is extensive among Photobacterium and Vibrio species. 


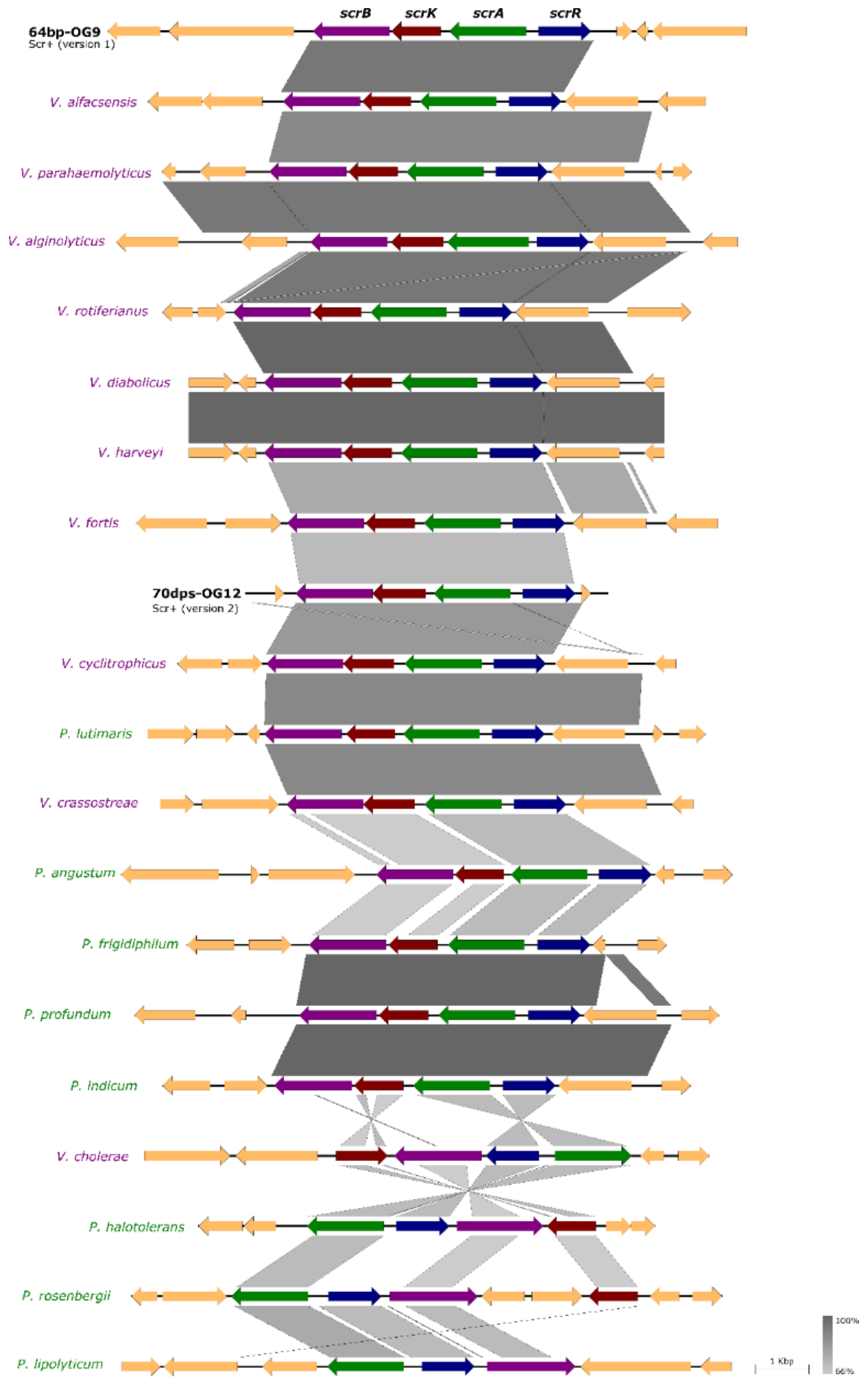

Figure 7. Comparative analysis of the sucrose degradation gene clusters in different species of Vibrio and Photobacterium, including the Pdd strains 64bp-OG9 (representative of version 1 of scr cluster) and 70dps-OG12 (version 2). 


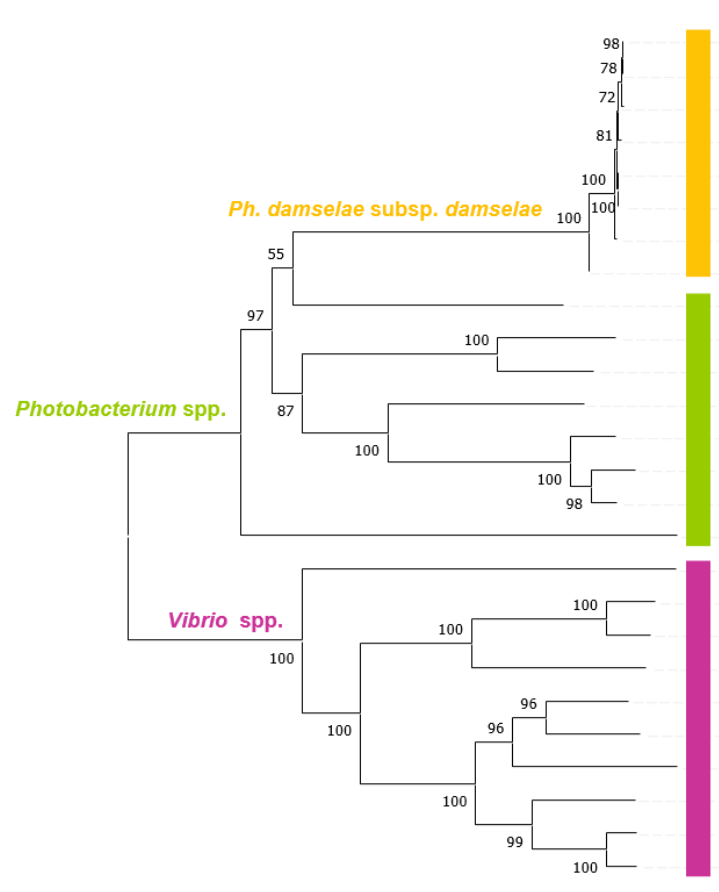

0.020

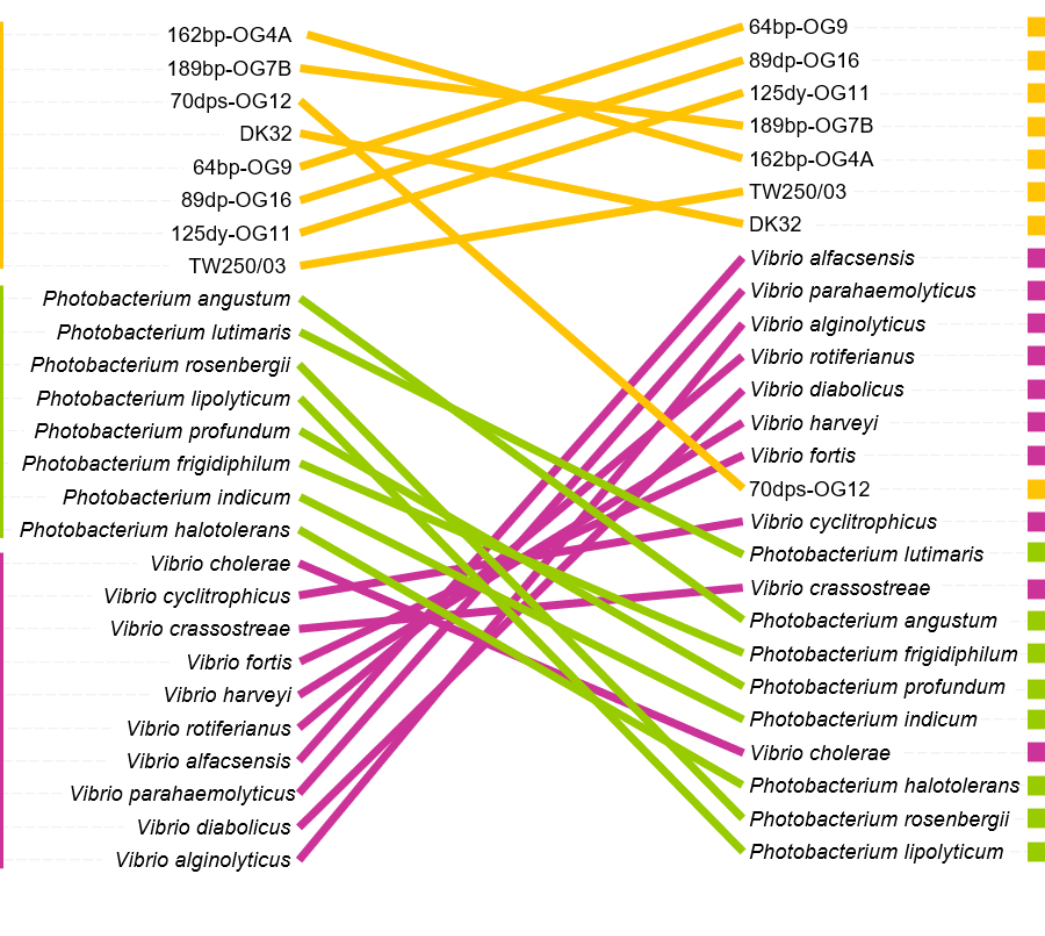

Species tree
Sucrose genes tree

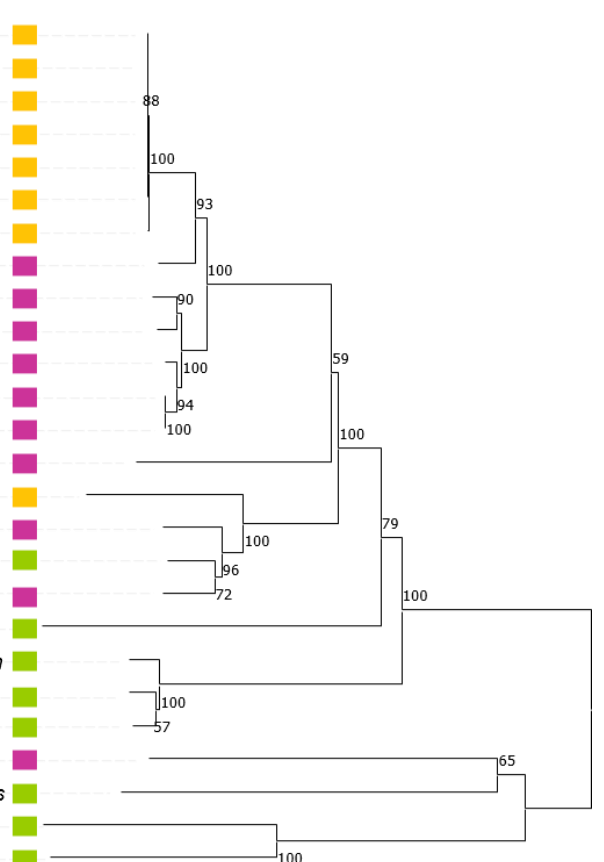

0.050

Figure 8. Comparison of the sucrose operon tree (right side) with the species tree (left side) for Scr ${ }^{+}$Pdd strains, and additional Photobacterium and Vibrio species. The sucrose operon tree was constructed based on the amino acid sequence alignment of the concatenated proteins ScrB, ScrK, ScrA, and ScrR. The species tree was constructed based on the amino acid sequence alignment of 8 concatenated proteins encoded by housekeeping genes $f t s Z, g a p A, g y r B, m r e B$, rec $A, p y r H$, top, and toxR. Species and strains are connected with different colors in both trees: Pdd strains (orange), Photobacterium spp. (green) and Vibrio spp. (purple). The noticeable incongruence between sucrose operon and species tree indicates that sucrose genes of $P d d$ are evolutionarily closely related to sucrose clusters of Vibrio species, while more distantly related to the sucrose clusters found in the majority of Photobacterium species. Bootstrap support values are displayed on the nodes. 


\section{Discussion}

$P d d$ (formerly known as $V$. damsela), is an important and emerging pathogen for marine animals and for humans [22]. An early review on pathogenic Vibrio species already highlighted that a 5\% of $P d d$ isolates were sucrose fermenters on TCBS agar [27]. Since then, various studies have unveiled the existence of $\mathrm{Scr}^{+} P d d$ isolates at varying frequencies. An extensive study that analyzed $71 P d d$ isolates from fish in Spain, reported that $4 \%$ were sucrose-fermenters [28]. In another study with Pdd strains from disease outbreaks in marine rainbow trout, one isolate out of 31 tested positive for sucrose fermentation [24]. A study reported the simultaneous isolation on a TCBS agar plate of yellow and green $P d d$ colonies from different organs of the same fish [29]. Notably, in a recent study, of $14 P d d$ strains isolated from diseased seabass in the Turkish coast of the Black Sea, 6 were able to ferment sucrose [30], which accounts for $40 \%$ of strains positive for this trait. Thus, albeit sucrose fermentation can be considered as an infrequent phenotype in this subspecies, the intraspecies variability of this metabolic trait needs to be taken into consideration, in order to avoid misidentification of potential Pdd strains in veterinary, clinical and environmental studies.

Even though sucrose fermentation tests are routinely used for identification and classification of species of the Vibrionaceae, the genetic basis of sucrose utilization in species of this family has received scarce attention. Homologues of the scr cluster genes described in the present study in $P d d$, were reported for the first time in $V$. alginolyticus in pioneering studies in the family Vibrionaceae [14-16]. Later, different investigations reported some data on sucrose utilization genes in $V$. cholerae [17-20] whereas, to the best of our knowledge, no functional and evolutionary analyses have been conducted in species of the genus Photobacterium so far. In this study, we describe two variants of a gene cluster that is required for the utilization of sucrose by $P d d$. Mutational analysis has demonstrated that scr $A$ gene encoding the predicted EIIBC component of the PTS sucrose transport system is essential for sucrose utilization as carbon source by $P d d$. In a previous study, the systematic genetic dissection of PTS systems in $V$. cholerae demonstrated that single deletion of VCA0563, a gene homologous to the Pdd scrA, was sufficient to abolish sucrose utilization [20], indicating that no redundant PTS functions existed in the $V$. cholerae genome capable of conferring the ability to take up sucrose. In contrast, $V$. cholerae showed to encode redundant PTS functions for the uptake of glucose, mannose and fructose [20]. We have here found that single deletion of $s c r A$ abolished sucrose utilization in Pdd DK32, demonstrating that this strain does not encode redundant PTS functions for the uptake of this disaccharide.

The scr clusters in some species of Enterobacteriaceae are known to be negatively controlled by the repressor encoded by scrR gene and thus genes encoding enzymes for sucrose catabolism are inducible by presence of sucrose in the medium $[62,63]$. The $P d d$ scr cluster also contains a homologue of $s c r R$ gene, but so far, no experimental evidence on the sucrose-inducible nature of $s c r$ clusters in the Photobacterium genus was available. We here have shown that growth of $P d d$ DK32 with sucrose as carbon source increased in 2.5-fold the transcriptional activity of the $s c r A$ promoter compared to growth in presence of glucose as carbon source, suggesting that sucrose metabolism in Pdd is subjected to a negative regulation similar to that described in some enterobacteria.

It was observed that presence of $s c r$ cluster genes imparted a unique colony phenotype to $P d d$ strains when grown in presence of high sucrose concentrations (15\%). The mechanisms underlying this phenotype await further and promising studies in $P d d$. Interestingly, a recent study pointed out that the $V$. cholerae VCA0653 gene encoding the sucrose-specific PTS component ScrA, was 30-fold downregulated on the phase variation switch from wild-type-colony phenotype to a rugose-colony phenotype, associated with advanced biofilm architecture [64]. This suggests that the ability to utilize sucrose would impair biofilm formation, and thus transition to a rugose phenotype correlates with a strong downregulation of sucrose uptake. Similarly, Lactobacillus strains grown on sucrose were found to produce dextrane, and it influenced self-aggregation and biofilm formation [65].

Carbohydrates constitute a main carbon source in bacteria [66]. Horizontal gene transfer enables bacteria to acquire new gene clusters that provide the recipient with novel metabolic activities to confront ecological changes $[67,68]$. Acquisition by horizontal transfer of genes for transport and 
catabolism of carbohydrates in members of the Vibrionaceae is being increasingly reported, as is the case of genes for cellobiose utilization [69], for degradation of algal polysaccharides [8], and genes of D-galactose metabolism [11], among others. Sucrose utilization clusters are not an exception to this, and previous studies have pointed out that sucrose gene clusters have been extensively exchanged among Eubacteria [21]. In the present study, the incongruence of phylogenies based on 8 representative housekeeping genes on the one side, and on the four scr genes on the other side, clearly revealed that genes for sucrose metabolism have undergone extensive horizontal transfer among genera and species within the family Vibrionaceae. Of the two scr cluster versions reported in the present study, the majority version 1 is likely chromosome I-borne considering that the conserved genome context upstream and downstream of sucrose genes corresponds to chromosome I genes in well studied Scr ${ }^{-}$Pdd genomes. In addition, the seven scr clusters of version 1 are invariably flanked by a duplicated 13-mer sequence that is a putative candidate to play a role in DNA acquisition. A recent study has reported that some regions of the $P d d$ genome constituted hot-spots for DNA acquisition, and such hypervariable regions were flanked by repeated sequences in tandem [24]. Similarly, sucrose utilization genes in enteropathogenic $E$. coli strains were found to be located within variable chromosomal regions rich in repeated sequences dubbed iap sequences [70]. The genetic context of version 2 represented by Pdd strain $70 \mathrm{dps}-\mathrm{OG} 12$ is uncertain, and it might be either chromosome- or plasmid borne. It is known that genes for sucrose metabolism in Enterobacteria are either chromosome-borne [71,72] or plasmid-borne [73-75]. Further studies are prompted in order to ascertain the existence of plasmid-borne scr clusters in members of the family Vibrionaceae.

The acquisition of sucrose metabolism genes by species of Vibrionaceae raises the question about what is the role of sucrose utilization in the ecology of Vibrios. Sucrose is the most abundant disaccharide on earth because of its origin in higher plant tissues. Early studies reported that green microalgae of the genus Trebouxia secreted sucrose to the culture medium [76], and nowadays it is widely known that green algae, cyanobacteria and purple bacteria synthesize sucrose [77]. Microalgae and cyanobacteria species accumulate sucrose as compatible osmolyte under osmotic stress, a process that has been mainly studied in freshwater environments [78-83]. A recent study reported the production of sucrose by marine species of Pyrocystis and Nannochloropsis genera [84]. Thus, either secreted by live cells or released upon cell lysis, sucrose is expected to be available as a carbon source in marine ecosystems. In support of this idea, a recent metabolomics study has reported the detection of abundant sugars, which included sucrose and trehalose, in marine ecosystems [85], and sucrose has also been detected as a major nutrient available in seagrass (Posidonia oceanica) meadows ecosystems [86]. It is also expected that the digestive tracts of marine herbivores as sea urchins and algae grazers among others, constitute a sucrose-rich niche for bacteria. Of note, a previous study has demonstrated that sucrose is a potent chemoattractant for Vibrio furnissii and this chemotaxis was suggested to be dependent on presence of an intact PTS system [87]. Hence, it is hypothesized that the scr gene clusters would confer advantage to the bacterial cells to use sucrose available in marine environment niches as a carbon source. Studies to test this hypothesis are currently under way.

Supplementary Materials: The following are available online at http://www.mdpi.com/2073-4425/11/11/1244/s1, Figure S1: Colony morphologies of $\mathrm{Scr}^{+}$and $\mathrm{Scr}^{-} \mathrm{Pdd}$ strains grown in either plain TSA-1 or in TSA-1 supplemented with $15 \%$ sucrose. Strains harboring the scr gene cluster form flat and translucent colonies in presence of high concentrations of sucrose, while strains lacking a functional scr cluster form convex and whitish colonies. The colony phenotypes of $\mathrm{Scr}^{+}$and $\mathrm{Scr}^{-}$strains are indistinguishable on TSA-1 without added sucrose.

Author Contributions: Conceptualization, S.A., A.V., A.V.B., and C.R.O.; Methodology: S.A., A.V., A.V.B., and C.R.O.; Software: A.V.; Formal Analysis: S.A., A.V., A.V.B. and C.R.O.; Investigation: S.A., A.V., A.V.B.; Resources: A.V., and C.R.O.; Data Curation: S.A., A.V., A.V.B., and C.R.O.; Writing-Original Draft Preparation: S.A.; Writing-Review and Editing: A.V., and C.R.O.; Supervision: A.V. and C.R.O.; Project Administration: C.R.O.; Funding Acquisition: C.R.O. All authors have read and agreed to the published version of the manuscript.

Funding: This work was supported by the Agencia Estatal de Investigación (AEI) of Spain co-funded by the FEDER Programme from the European Union (grants no. AGL2016-79738-R and PID2019-110558RB-I00) and by Xunta de Galicia (Spain) (grant no. ED431C 2018/18). 
Conflicts of Interest: The authors declare no conflict of interest. The funders had no role in the design of the study; in the collection, analyses, or interpretation of data; in the writing of the manuscript, or in the decision to publish the results.

\section{References}

1. Thompson, F.L.; Iida, T.; Swings, J. Biodiversity of vibrios. Microbiol. Mol. Biol. Rev. 2004, 68, 403-431. [CrossRef]

2. Baker-Austin, C.; Oliver, J.D.; Alam, M.; Ali, A.; Waldor, M.K.; Qadri, F.; Martinez-Urtaza, J. Vibrio spp. infections. Nat. Rev. Dis. Prim. 2018, 4, 8. [CrossRef] [PubMed]

3. Takemura, A.F.; Chien, D.M.; Polz, M.F. Associations and dynamics of Vibrionaceae in the environment, from the genus to the population level. Front. Microbiol. 2014, 5, 38. [CrossRef] [PubMed]

4. Reen, F.J.; Almagro-Moreno, S.; Ussery, D.; Boyd, E.F. The genomic code: Inferring Vibrionaceae niche specialization. Nat. Rev. Microbiol. 2006, 4, 697-704. [CrossRef] [PubMed]

5. Thompson, C.C.; Vicente, A.C.P.; Souza, R.C.; Vasconcelos, A.T.R.; Vesth, T.; Alves, N.; Ussery, D.W.; Iida, T.; Thompson, F.L. Genomic taxonomy of vibrios. BMC Evol. Biol. 2009, 9, 258. [CrossRef]

6. Urbanczyk, H.; Ast, J.C.; Dunlap, P.V. Phylogeny, genomics, and symbiosis of Photobacterium. FEMS Microbiol. Rev. 2011, 35, 324-342. [CrossRef]

7. Le Roux, F.; Wegner, K.M.; Baker-Austin, C.; Vezzulli, L.; Osorio, C.R.; Amaro, C.; Ritchie, J.M.; Defoirdt, T.; Destoumieux-Garzón, D.; Blokesch, M.; et al. The emergence of Vibrio pathogens in Europe: Ecology, evolution, and pathogenesis (Paris, 11-12 March 2015). Front. Microbiol. 2015, 6, 830.

8. Hehemann, J.-H.; Arevalo, P.; Datta, M.S.; Yu, X.; Corzett, C.H.; Henschel, A.; Preheim, S.P.; Timberlake, S.; Alm, E.J.; Polz, M.F. Adaptive radiation by waves of gene transfer leads to fine-scale resource partitioning in marine microbes. Nat. Commun. 2016, 7, 1-10. [CrossRef]

9. Machado, H.; Gram, L. Comparative genomics reveals high genomic diversity in the genus Photobacterium. Front. Microbiol. 2017, 8, 1204. [CrossRef]

10. Le Roux, F.; Blokesch, M. Eco-evolutionary dynamics linked to horizontal gene transfer in vibrios. Annu. Rev. Microbiol. 2018. [CrossRef]

11. Regmi, A.; Boyd, E.F. Carbohydrate metabolic systems present on genomic islands are lost and gained in Vibrio parahaemolyticus. BMC Microbiol. 2019, 19, 112. [CrossRef] [PubMed]

12. Kobayashi, T.; Enomoto, S.; Sakazaki, R.; Kuwahara, S. A new selective isolation medium for pathogenic vibrios: TCBS agar. Jap. J. Bact. 1963, 18, 387-391. [CrossRef]

13. Scholle, R.R.; Coyne, V.E.; Maharaj, R.; Robb, F.T.; Woods, D.R. Expression and regulation of a Vibrio alginolyticus sucrose utilization system cloned in Escherichia coli. J. Bacteriol. 1987, 169, 2685-2690. [CrossRef]

14. Scholle, R.R.; Robb, S.M.; Robb, F.T.; Woods, D.R. Nucleotide sequence and analysis of the Vibrio alginolyticus sucrase gene (scrB). Gene 1989, 80, 49-56. [CrossRef]

15. Blatch, G.L.; Scholle, R.R.; Woods, D.R. Nucleotide sequence and analysis of the Vibrio alginolyticus sucrose uptake-encoding region. Gene 1990, 95, 17-23. [CrossRef]

16. Blatch, G.L.; Woods, D.R. Nucleotide sequence and analysis of the Vibrio alginolyticus scr repressor-encoding gene (scrR). Gene 1991, 101, 45-50. [CrossRef]

17. Houot, L.; Chang, S.; Absalon, C.; Watnick, P.I. Vibrio cholerae phosphoenolpyruvate phosphotransferase system control of carbohydrate transport, biofilm formation, and colonization of the germfree mouse intestine. Infect. Immun. 2010, 78, 1482-1494. [CrossRef]

18. Wang, D.; Wang, H.; Zhou, Y.; Zhang, Q.; Zhang, F.; Du, P.; Wang, S.; Chen, C.; Kan, B. Genome sequencing reveals unique mutations in characteristic metabolic pathways and the transfer of virulence genes between $V$. mimicus and $V$. cholerae. PLoS ONE 2011, 6, e21299. [CrossRef]

19. Garza, D.R.; Thompson, C.C.; Loureiro, E.C.B.; Dutilh, B.E.; Inada, D.T.; Junior, E.C.S.; Cardoso, J.F.; Nunes, M.R.T.; de Lima, C.P.S.; Silvestre, R.V.D. Genome-wide study of the defective sucrose fermenter strain of Vibrio cholerae from the Latin American cholera epidemic. PLoS ONE 2012, 7, e37283. [CrossRef]

20. Hayes, C.A.; Dalia, T.N.; Dalia, A.B. Systematic genetic dissection of PTS in Vibrio cholerae uncovers a novel glucose transporter and a limited role for PTS during infection of a mammalian host. Mol. Microbiol. 2017, 104, 568-579. [CrossRef] 
21. Reid, S.J.; Abratt, V.R. Sucrose utilisation in bacteria: Genetic organisation and regulation. Appl. Microbiol. Biotechnol. 2005, 67, 312-321. [CrossRef] [PubMed]

22. Osorio, C.R.; Vences, A.; Matanza, X.M.; Terceti, M.S. Photobacterium damselae subsp. damselae, a generalist pathogen with unique virulence factors and high genetic diversity. J. Bacteriol. 2018, 15, e00002-18. [CrossRef] [PubMed]

23. Hundenborn, J.; Thurig, S.; Kommerell, M.; Haag, H.; Nolte, O. Severe wound infection with Photobacterium damselae ssp. damselae and Vibrio harveyi, following a laceration injury in marine environment: A case report and review of the literature. Case Rep. Med. 2013, 2013, 610632. [CrossRef] [PubMed]

24. Terceti, M.S.; Vences, A.; Matanza, X.M.; Dalsgaard, I.; Pedersen, K.; Osorio, C.R. Molecular epidemiology of Photobacterium damselae subsp. damselae outbreaks in marine rainbow trout farms reveals extensive horizontal gene transfer and high genetic diversity. Front. Microbiol. 2018, 9, 2155. [CrossRef] [PubMed]

25. Osorio, C.R. Photobacterium damselae: How horizontal gene transfer shaped two different pathogenic lifestyles in a marine bacterium. In Horizontal Gene Transfer: Breaking Borders between Living Kingdoms; Villa, T.G., Viñas, M., Eds.; Springer: Cham, Switzerland, 2019; pp. 175-199.

26. Vences, A.; Abushattal, S.; Matanza, X.M.; Dubert, J.; Uzun, E.; Ogut, H.; Osorio, C.R. Highly transferable pAQU-related plasmids encoding multidrug resistance are widespread in the human and fish pathogen Photobacterium damselae subsp. damselae in aquaculture areas in the Black Sea. Microb. Ecol. 2020. [CrossRef] [PubMed]

27. Farmer, J.J., III; Hickman-Brenner, F.W.; Kelly, M.T. Vibrio. In Manual of Clinical Microbiology, 4th ed.; Lennette, E.H., Balows, A., Hausler, W.J., Shadomy, H.J., Eds.; American Society for Microbiology: Washington, DC, USA, 1985; pp. 282-301.

28. Botella, S.; Pujalte, M.; Macián, M.; Ferrús, M.; Hernández, J.; Garay, E. Amplified fragment length polymorphism (AFLP) and biochemical typing of Photobacterium damselae subsp. damselae. J. Appl. Microbiol. 2002, 93, 681-688. [CrossRef] [PubMed]

29. Zhao, D.H.; Sun, J.J.; Liu, L.; Zhao, H.H.; Wang, H.F.; Liang, L.Q.; Liu, L.B.; Li, G.F. Characterization of two phenotypes of Photobacterium damselae subsp. damselae isolated from diseased juvenile Trachinotus ovatus reared in cage mariculture. J. World Aquac. Soc. 2009, 40, 281-289. [CrossRef]

30. Terceti, M.S.; Ogut, H.; Osorio, C.R. Photobacterium damselae subsp. damselae, an emerging fish pathogen in the Black Sea: Evidence of a multiclonal origin. Appl. Environ. Microbiol. 2016, 82, 3736-3745. [CrossRef]

31. Tao, Z.; Shen, C.; Zhou, S.-M.; Yang, N.; Wang, G.-L.; Wang, Y.-J.; Xu, S.-L. An outbreak of Photobacterium damselae subsp. damselae infection in cultured silver pomfret Pampus argenteus in Eastern China. Aquaculture 2018, 492, 201-205. [CrossRef]

32. Love, M.; Teebken-Fisher, D.; Hose, J.E.; Farmer, J.J., 3rd; Hickman, F.W.; Fanning, G.R. Vibrio damsela, a marine bacterium, causes skin ulcers on the damselfish Chromis punctipinnis. Science 1981, 214, 1139-1140. [CrossRef]

33. Fouz, B.; Larsen, J.L.; Nielsen, B.; Barja, J.L.; Toranzo, A.E. Characterization of Vibrio damsela strains isolated from turbot Scophthalmus maximus in Spain. Dis. Aquat. Organ. 1992, 12, 155-166. [CrossRef]

34. Vences, A.; Rivas, A.J.; Lemos, M.L.; Husmann, M.; Osorio, C.R. Chromosome-encoded hemolysin, phospholipase, and collagenase in plasmidless isolates of Photobacterium damselae subsp. damselae contribute to virulence for fish. Appl. Environ. Microbiol. 2017, 83, e00401-17. [CrossRef] [PubMed]

35. Vera, P. First isolation of Vibrio damsela from sea bream (Sparus aurata). Bull. Eur. Assoc. Fish Pathol. 1991, 11, 112.

36. Pedersen, K.; Dalsgaard, I.; Larsen, J.L. Vibrio damsela associated with diseased fish in Denmark. Appl. Environ. Microbiol. 1997, 63, 3711-3715. [CrossRef]

37. Pedersen, K.; Skall, H.F.; Lassen-Nielsen, A.M.; Bjerrum, L.; Olesen, N.J. Photobacterium damselae subsp. damselae, an emerging pathogen in Danish rainbow trout, Oncorhynchus mykiss (Walbaum), mariculture. J. Fish Dis. 2009, 32, 465-472. [CrossRef]

38. Kreger, A.S. Cytolytic activity and virulence of Vibrio damsela. Infect. Immun. 1984, 44, 326-331. [CrossRef]

39. Grimes, D.J.; Colwell, R.R.; Stemmler, J.; Hada, H.; Maneval, D.; Hetrick, F.M.; May, E.B.; Jones, R.T.; Stoskopf, M. Vibrio species as agents of elasmobranch disease. Helgoländer Meeresunters 1984, 37, 309-315. [CrossRef]

40. Matanza, X.M.; Osorio, C.R. Exposure of the opportunistic marine pathogen Photobacterium damselae subsp. damselae to human body temperature is a stressful condition that shapes the transcriptome, viability, cell morphology, and virulence. Front. Microbiol. 2020, 11, 1771. [CrossRef] 
41. Herrero, M.; de Lorenzo, V.; Timmis, K.N. Transposon vectors containing non-antibiotic resistance selection markers for cloning and stable chromosomal insertion of foreign genes in gram-negative bacteria. J. Bacteriol. 1990, 172, 6557-6567. [CrossRef]

42. Parales, R.E.; Harwood, C.S. Construction and use of a new broad-host-range lacZ transcriptional fusion vector, pHRP309, for Gram- bacteria. Gene 1993, 133, 23-30. [CrossRef]

43. Wang, R.F.; Kushner, S.R. Construction of versatile low-copy-number vectors for cloning, sequencing and gene expression in Escherichia coli. Gene 1991, 100, 195-199. [CrossRef]

44. Mouriño, S.; Osorio, C.R.; Lemos, M.L. Characterization of heme uptake cluster genes in the fish pathogen Vibrio anguillarum. J. Bacteriol. 2004, 186, 6159-6167. [CrossRef] [PubMed]

45. Nurk, S.; Bankevich, A.; Antipov, D.; Gurevich, A.A.; Korobeynikov, A.; Lapidus, A.; Prjibelski, A.D.; Pyshkin, A.; Sirotkin, A.; Sirotkin, Y.; et al. Assembling single-cell genomes and mini-metagenomes from chimeric MDA products. J. Comput. Biol. 2013, 20, 714-737. [CrossRef]

46. Tatusova, T.; DiCuccio, M.; Badretdin, A.; Chetvernin, V.; Nawrocki, E.P.; Zaslavsky, L.; Lomsadze, A.; Pruitt, K.D.; Borodovsky, M.; Ostell, J. NCBI Prokaryotic Genome Annotation Pipeline. Nucleic Acids Res. 2016, 44, 6614-6624. [CrossRef]

47. Miller, J.H. Experiments in Molecular Genetics; Cold Spring Harbor Laboratory: Cold Spring Harbor, NY, USA, 1972.

48. Miller, J.H. A Short Course in Bacterial Genetics; Cold Spring Harbor Laboratory Press: Cold Spring Harbor, NY, USA, 1992.

49. Aziz, R.K.; Bartels, D.; Best, A.A.; DeJongh, M.; Disz, T.; Edwards, R.A.; Formsma, K.; Gerdes, S.; Glass, E.M.; Kubal, M.; et al. The RAST Server: Rapid annotations using subsystems technology. BMC Genom. 2008, 9, 75. [CrossRef]

50. El-Gebali, S.; Mistry, J.; Bateman, A.; Eddy, S.R.; Luciani, A.; Potter, S.C.; Qureshi, M.; Richardson, L.J.; Salazar, G.A.; Smart, A.; et al. The Pfam protein families database in 2019. Nucleic Acids Res. 2019, 47, D427-D432. [CrossRef]

51. Sullivan, M.J.; Petty, N.K.; Beatson, S.A. Easyfig: A genome comparison visualizer. Bioinformatics 2011, 27, 1009-1010. [CrossRef]

52. Darling, A.C.; Mau, B.; Blattner, F.R.; Perna, N.T. Mauve: Multiple alignment of conserved genomic sequence with rearrangements. Genome Res. 2004, 14, 1394-1403. [CrossRef]

53. Darling, A.E.; Mau, B.; Perna, N.T. progressiveMauve: Multiple genome alignment with gene gain, loss and rearrangement. PLoS ONE 2010, 5, e11147. [CrossRef]

54. Pérez-Cataluña, A.; Lucena, T.; Tarazona, E.; Arahal, D.R.; Macián, M.C.; Pujalte, M.J. An MLSA approach for the taxonomic update of the Splendidus clade, a lineage containing several fish and shellfish pathogenic Vibrio spp. Syst. Appl. Microbiol. 2016, 39, 361-369. [CrossRef]

55. Pascual, J.; Macián, M.C.; Arahal, D.R.; Garay, E.; Pujalte, M.J. Multilocus sequence analysis of the central clade of the genus Vibrio by using the $16 \mathrm{~S}$ rRNA, recA, pyrH, rpoD, gyrB, rctB and toxR genes. Int. J. Syst. Evol. Microbiol. 2010, 60, 154-165. [CrossRef]

56. Maddison, W.P.; Maddison, D.R. Mesquite: A Modular System for Evolutionary Analysis. Version 3.61. Available online: http://www.mesquiteproject.org (accessed on 29 February 2020).

57. Kumar, S.; Stecher, G.; Li, M.; Knyaz, C.; Tamura, K. MEGA X: Molecular evolutionary genetics analysis across computing platforms. Mol. Biol. Evol. 2018, 35, 1547-1549. [CrossRef] [PubMed]

58. Saitou, N.; Nei, M. The neighbor-joining method: A new method for reconstructing phylogenetic trees. Mol. Biol. Evol. 1987, 4, 406-425.

59. Tamura, K.; Nei, M.; Kumar, S. Prospects for inferring very large phylogenies by using the neighbor-joining method. Proc. Natl. Acad. Sci. USA 2004, 101, 11030-11035. [CrossRef] [PubMed]

60. Deutscher, J.; Aké, F.M.D.; Derkaoui, M.; Zébré, A.C.; Cao, T.N.; Bouraoui, H.; Kentache, T.; Mokhtari, A.; Milohanic, E.; Joyet, P. The bacterial phosphoenolpyruvate: Carbohydrate phosphotransferase system: Regulation by protein phosphorylation and phosphorylation-dependent protein-protein interactions. Microbiol. Mol. Biol. Rev. 2014, 78, 231-256. [CrossRef]

61. McCoy, J.G.; Ren, Z.; Stanevich, V.; Lee, J.; Mitra, S.; Levin, E.J.; Poget, S.; Quick, M.; Im, W.; Zhou, M. The structure of a sugar transporter of the glucose EIIC superfamily provides insight into the elevator mechanism of membrane transport. Structure 2016, 24, 956-964. [CrossRef]

62. Jahrels, K.; Lengeler, J.W. Molecular analysis of two ScrR repressors and of a ScrR-FruR hybrid repressor for sucrose and D-fructose specific regulons from enteric bacteria. Mol. Microbiol. 1993, 9, 195-209. [CrossRef] 
63. Bogs, J.; Geider, K. Molecular analysis of sucrose metabolism of Erwinia amylovora and influence on bacterial virulence. J. Bacteriol. 2000, 182, 5351-5358. [CrossRef]

64. Lambert, B.; Dassanayake, M.; Oh, D.-H.; Garrett, S.B.; Lee, S.-Y.; Pettis, G.S. A novel phase variant of the cholera pathogen shows stress-adaptive cryptic transcriptomic signatures. BMC Genom. 2016, 17, 914. [CrossRef]

65. Nácher-Vázquez, M.; Iturria, I.; Zarour, K.; Mohedano, M.L.; Aznar, R.; Pardo, M.Á.; López, P. Dextran production by Lactobacillus sakei MN1 coincides with reduced autoagglutination, biofilm formation and epithelial cell adhesion. Carbohydr. Polym. 2017, 168, 22-31. [CrossRef]

66. Durica-Mitic, S.; Goepel, Y.; Görke, B. Carbohydrate utilization in bacteria: Making the most out of sugars with the help of small regulatory RNAs. Microbiol. Spectr. 2018, 6. [CrossRef]

67. Ochman, H.; Lawrence, J.G.; Groisman, E.A. Lateral gene transfer and the nature of bacterial innovation. Nature 2000, 405, 299-304. [CrossRef]

68. Hazen, T.H.; Pan, L.; Gu, J.-D.; Sobecky, P.A. The contribution of mobile genetic elements to the evolution and ecology of Vibrios. FEMS Microbiol. Ecol. 2010, 74, 485-499. [CrossRef] [PubMed]

69. Adin, D.M.; Visick, K.L.; Stabb, E.V. Identification of a cellobiose utilization gene cluster with cryptic beta-galactosidase activity in Vibrio fischeri. Appl. Environ. Microbiol. 2008, 74, 4059-4069. [CrossRef]

70. Treviño-Quintanilla, L.G.; Escalante, A.; Caro, A.D.; Martínez, A.; González, R.; Puente, J.L.; Bolívar, F.; Gosset, G. The phosphotransferase system-dependent sucrose utilization regulon in enteropathogenic Escherichia coli strains is located in a variable chromosomal region containing iap sequences. J. Mol. Microbiol. Biotechnol. 2007, 13, 117-125. [CrossRef]

71. Alaeddinoglu, N.G.; Charles, H.P. Transfer of a gene for sucrose utilization into Escherichia coli k12, and consequent failure of expression of genes for D-serine utilization. Microbiology 1979, 110, 47-59. [CrossRef]

72. Bockmann, J.; Heuel, H.; Lengeler, J.W. Characterization of a chromosomally encoded, non-PTS metabolic pathway for sucrose utilization in Escherichia coli EC3132. Mol. Gen. Genet. MGG 1992, 235, 22-32. [CrossRef]

73. Wohlhieter, J.A.; Lazere, J.R.; Snellings, N.J.; Johnson, E.M.; Synenki, R.M.; Baron, L.S. Characterization of transmissible genetic elements from sucrose-fermenting Salmonella strains. J. Bacteriol. 1975, 122, 401-406. [CrossRef]

74. Schmid, K.; Ebner, R.; Altenbuchner, J.; Schmitt, R.; Lengeler, J.W. Plasmid-mediated sucrose metabolism in Escherichia coli K12: Mapping of the scr genes of pUR400. Mol. Microbiol. 1988, 2, 1-8. [CrossRef]

75. Hardesty, C.; Ferran, C.; DiRienzo, J.M. Plasmid-mediated sucrose metabolism in Escherichia coli: Characterization of scrY, the structural gene for a phosphoenolpyruvate-dependent sucrose phosphotransferase system outer membrane porin. J. Bacteriol. 1991, 173, 449-456. [CrossRef]

76. Maruo, B.; Hattori, T.; Takahashi, H. Excretion of ribitol and sucrose by green algae into the culture medium. Agric. Biol. Chem. 1965, 29, 1084-1089. [CrossRef]

77. Lunn, J.E. Evolution of sucrose synthesis. Plant Physiol. 2002, 128, 1490-1500. [CrossRef] [PubMed]

78. Hagemann, M. Molecular biology of cyanobacterial salt acclimation. FEMS Microbiol. Rev. 2011, 35, 87-123. [CrossRef]

79. Bremauntz, M.; Torres-Bustillos, L.G.; Cañizares-Villanueva, R.; Duran-Paramo, E.; Fernández-Linares, L. Trehalose and sucrose osmolytes accumulated by algae as potential raw material for bioethanol. Nat. Resour. 2011, 2, 173. [CrossRef]

80. Du, W.; Liang, F.; Duan, Y.; Tan, X.; Lu, X. Exploring the photosynthetic production capacity of sucrose by cyanobacteria. Metab. Eng. 2013, 19, 17-25. [CrossRef]

81. Kolman, M.A.; Nishi, C.N.; Perez-Cenci, M.; Salerno, G.L. Sucrose in cyanobacteria: From a salt-response molecule to play a key role in nitrogen fixation. Life 2015, 5, 102-126. [CrossRef]

82. Kolman, M.A.; Salerno, G.L. Sucrose in bloom-forming cyanobacteria: Loss and gain of genes involved in its biosynthesis. Environ. Microbiol. 2016, 18, 439-449. [CrossRef]

83. Kirsch, F.; Klähn, S.; Hagemann, M. Salt-regulated accumulation of the compatible solutes sucrose and glucosylglycerol in cyanobacteria and its biotechnological potential. Front. Microbiol. 2019, 10, 2139. [CrossRef]

84. Carrasco-Reinado, R.; Escobar, A.; Carrera, C.; Guarnizo, P.; Vallejo, R.A.; Fernández-Acero, F.J. Valorization of microalgae biomass as a potential source of high-value sugars and polyalcohols. LWT-Food Sci. Technol. 2019, 114, 108385. [CrossRef] 
85. Sogin, E.M.; Puskas, E.; Dubilier, N.; Liebeke, M. Marine metabolomics: A method for nontargeted measurement of metabolites in seawater by gas chromatography-mass spectrometry. mSystems 2019, 4 . [CrossRef]

86. Martínez-Crego, B.; Vizzini, S.; Califano, G.; Massa-Gallucci, A.; Andolina, C.; Gambi, M.C.; Santos, R. Resistance of seagrass habitats to ocean acidification via altered interactions in a tri-trophic chain. Sci. Rep. 2020, 10, 1-13. [CrossRef] [PubMed]

87. Yu, C.; Bassler, B.L.; Roseman, S. Chemotaxis of the marine bacterium Vibrio furnissii to sugars. A potential mechanism for initiating the chitin catabolic cascade. J. Biol. Chem. 1993, 268, 9405-9409. [PubMed]

Publisher's Note: MDPI stays neutral with regard to jurisdictional claims in published maps and institutional affiliations.

(C) 2020 by the authors. Licensee MDPI, Basel, Switzerland. This article is an open access article distributed under the terms and conditions of the Creative Commons Attribution (CC BY) license (http://creativecommons.org/licenses/by/4.0/). 